\title{
Tracheostomy: Epidemiology, Indications, Timing, Technique, and Outcomes
}

Nora H Cheung MD and Lena M Napolitano MD

\author{
Introduction \\ Overview of Tracheostomy \\ Terminology and Definitions \\ History of Tracheostomy \\ Epidemiology \\ Indications for Tracheostomy \\ Complications of Tracheostomy \\ Outcomes of Tracheostomy \\ Timing of Tracheostomy \\ Observational Studies \\ 2005 Meta-Analysis (4 Studies) \\ Large Retrospective Cohort Study \\ 2010 Early Versus Late Tracheotomy Study \\ 2011 Meta-Analysis (7 Studies) \\ 2012 Meta-Analysis (4 Studies) \\ 2013 TracMan \\ Optimal Timing of Tracheostomy Based on Recent Randomized \\ Controlled Trials \\ Limitations of Tracheostomy Timing Studies \\ Charges and Compensation for Tracheostomy \\ Patients Who Would Benefit From Early Tracheostomy? \\ Trauma \\ Traumatic Brain Injury \\ Spinal Cord Injury \\ Neurosurgical Patients \\ Mechanically Ventilated Patients With COPD \\ Tracheostomy Technique \\ Open Surgical Versus Percutaneous Tracheostomy \\ Types of Percutaneous Tracheostomy \\ Comparison of 2 Single Tapered Dilator Percutaneous \\ Dilatational Tracheostomy Sets \\ Challenges With Percutaneous Dilatational Tracheostomy and \\ New Solutions \\ Two New Percutaneous Tracheostomy Procedures \\ High-Risk Patients and Percutaneous Dilatational Tracheostomy \\ Procedural Cost of Tracheostomy \\ Tracheostomy Decannulation \\ Additional Recent Advances in Tracheostomy \\ Real-time Ultrasound \\ Multidisciplinary Tracheostomy Team \\ National Tracheostomy Safety Project \\ Conclusions
}




\section{TRACHEOSTOMY}

Tracheostomy is a common procedure performed in critically ill patients requiring prolonged mechanical ventilation for acute respiratory failure and for airway issues. The ideal timing (early vs late) and techniques (percutaneous dilatational, other new percutaneous techniques, open surgical) for tracheostomy have been topics of considerable debate. In this review, we address general issues regarding tracheostomy (epidemiology, indications, and outcomes) and specifically review the literature regarding appropriate timing of tracheostomy tube placement. Based on evidence from 2 recent large randomized trials, it is reasonable to wait at least $10 \mathrm{~d}$ to be certain that a patient has an ongoing need for mechanical ventilation before consideration of tracheostomy. Percutaneous tracheostomy with flexible bronchoscopy guidance is recommended, and optimal percutaneous techniques, indications, and contraindications and results in high-risk patients (coagulopathy, thrombocytopenia, obesity) are reviewed. Additional issues related to tracheostomy diagnosis-related groups, charges, and procedural costs are reviewed. New advances regarding tracheostomy include the use of real-time ultrasound guidance for percutaneous tracheostomy in high-risk patients. New tracheostomy tubes (tapered with low-profile cuffs that fit better on the tapered dilators, longer percutaneous tracheostomy tubes) are discussed for optimal use with percutaneous dilatational tracheostomy. Two new percutaneous techniques, a balloon inflation technique (Dolphin) and the PercuTwist procedure, are reviewed. The efficacy of tracheostomy teams and tracheostomy hospital services with standardized protocols for tracheostomy insertion and care has been associated with improved outcomes. Finally, the UK National Tracheostomy Safety Project developed standardized resources for education of both health care providers and patients, including emergency algorithms for tracheostomy incidents, and serves as an excellent educational resource in this important area. Key words: tracheostomy; timing; percutaneous dilatational; open; outcomes; complications. [Respir Care 2014;59(6):895-919. (C) 2014 Daedalus Enterprises]

\section{Introduction}

Acute respiratory failure requiring mechanical ventilation is common in critical illness, and progressive advancements in the understanding of and technologies for the care of the critically ill have resulted in an increase in the number of patients who remain dependent on mechanical ventilation for prolonged periods of time. Prolonged translaryngeal endotracheal intubation increases the risk of ventilator-associated pneumonia (VAP) by bypassing and disabling the laryngeal mechanisms, promoting oropharyngeal contamination of the bronchial tree and lung. ${ }^{1}$ In addition, prolonged translaryngeal endotracheal intubation

The authors are affiliated with the Division of Acute Care Surgery, Department of Surgery, University of Michigan, Ann Arbor, Michigan.

Dr Napolitano presented a version of this paper at the 52nd RESPIRATORY CARE Journal Conference, "Adult Artificial Airways and Airway Adjuncts" held June 14 and 15, 2013, in St Petersburg, Florida.

The authors have disclosed no conflicts of interests.

Correspondence: Lena M Napolitano MD, Department of Surgery, University of Michigan Health System, Room 1C340A-UH, University Hospital, 1500 East Medical Drive, Ann Arbor, MI 48109-0033. E-mail: lenan@umich.edu.

DOI: $10.4187 /$ respcare.02971 is associated with the development of sinusitis $^{2}$ and may cause severe laryngeal and tracheal damage. ${ }^{3}$

Placement of a tracheostomy has become a viable alternative to prolonged endotracheal intubation, with the benefits of improving patient comfort, reducing need for sedation, lowering airway resistance, and allowing for easier airway care. ${ }^{4-6}$ Complications related to tracheostomies include pneumothorax, bleeding, subglottic stenosis, tracheoesophageal fistula, vocal cord dysfunction, stomal granulation, persistent tracheal fistula, and scarring. ${ }^{7}$

The indications, technique, timing, and selection of critically ill patients for tracheostomy have been topics of considerable debate. In this review, we address general issues regarding tracheostomy and specifically review the literature on the subjects of appropriate timing of tracheostomy tube placement and specific techniques of tracheostomy tube placement.

\section{Overview of Tracheostomy}

\section{Terminology and Definitions}

The following terms and definitions are used. We will use the term tracheostomy, referring to a tracheal opening with attachment to the skin, in this review. A tracheotomy refers to any procedure that involves opening the trachea (temporary opening). A tracheostomy is a procedure that exteriorizes the trachea to the skin of the neck, producing 


\section{TRACHEOSTOMY}

a more permanent fistula/opening. A tracheostoma is a permanent opening into the trachea through the neck; it also refers to the opening after permanent laryngectomy.

\section{History of Tracheostomy}

The first known depiction of tracheostomy is from 3600 BC, on Egyptian tablets. ${ }^{8}$ According to legend, Alexander the Great used his sword to open the airway of a soldier choking from a bone lodged in his throat. The writings of Aretaeus (2nd century AD) and Galen (2nd to 3rd century AD) document tracheostomy performed by the Greek physician Asklepiades about $100 \mathrm{BC} .^{9}$ Additional contributions of medieval Islamic physicians to the history of tracheostomy have been detailed recently. ${ }^{10}$ The first scientific reliable description of successful tracheostomy by the surgeon who performed it was by Antonio Musa Brasavola in 1546, for relief of airway obstruction from enlarged tonsils. ${ }^{11}$ From 1546 to 1833 , only 28 successful tracheostomies were recorded, and almost all were for relief of upper airway obstruction. In the early 20th century, tracheostomy was made much safer, and the technical aspects of the procedure were refined and described in detail by the famous surgeon Chevalier Jackson. ${ }^{12}$ Tracheostomy was subsequently used extensively during the polio epidemic. ${ }^{13}$ At present, tracheostomy is more commonly used for prolonged mechanical ventilation rather than for upper airway obstruction.

\section{Epidemiology}

Each year, 800,000 United States residents undergo mechanical ventilation for acute respiratory insufficiency, often for a period of days or weeks. ${ }^{14}$ Some studies have documented a significant increase in the number of patients requiring mechanical ventilation. ${ }^{15,16}$ North Carolina documented a statewide $11 \%$ increase in adult mechanical ventilation, from $284 / 100,000$ in 1996 to $314 / 100,000$ in 2002 , with the greatest increase in the younger age groups (19\% increase for $18-64-y-o l d$ adults). ${ }^{17} \mathrm{Up}$ to $34 \%$ of patients who need mechanical ventilation for $>48 \mathrm{~h}$ receive a tracheostomy for prolonged mechanical ventilation. ${ }^{18}$ In the United States, 64,000 tracheostomy tubes were placed in $1996 .{ }^{19}$ The average number of tracheostomies performed annually in the United States now is $>100,000 .{ }^{20}$

In the state of North Carolina between 1993 and 2002, the incidence of tracheostomy for prolonged mechanical ventilation increased in all age groups from 8.3 to 24.2/100,000, most significantly among patients $<55$ y old. This was associated with a significant decrease in mortality (39\% vs $25 \%$ ), median ventilator days (12 vs 10), and median stay (47 vs 33 d). By 2002, patients were almost 3 times less likely to be discharged to home independently and twice as likely to be sent to a skilled nursing facility. ${ }^{21}$
Table 1. Indications for Tracheostomy

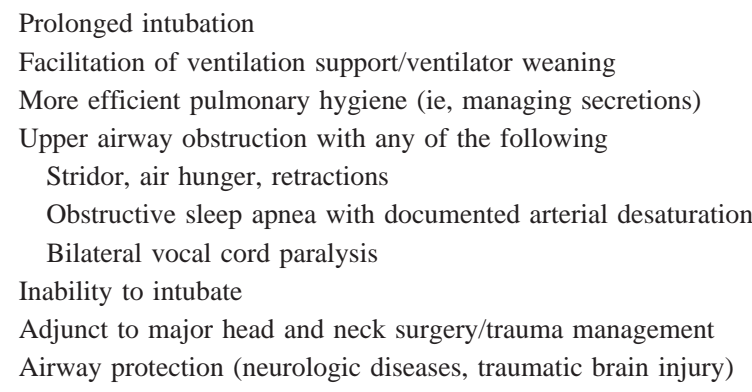

\section{Indications for Tracheostomy}

General indications for the placement of tracheostomy include acute respiratory failure with the expected need for prolonged mechanical ventilation, failure to wean from mechanical ventilation, upper airway obstruction, difficult airway, and copious secretions (Table 1).22,23 The most common indications for tracheostomy are (1) acute respiratory failure and need for prolonged mechanical ventilation (representing two thirds of all cases) and (2) traumatic or catastrophic neurologic insult requiring airway, or mechanical ventilation or both. Upper airway obstruction is a less common indication for tracheostomy.

The most common reason for tracheostomy in the ICU is to provide access for prolonged mechanical ventilation. Observational studies document that $\sim 10 \%$ of mechanically ventilated patients undergo tracheostomy, but there is significant variability with regard to optimal timing and optimal patient selection. ${ }^{24,25}$

There is also significant unexplained variation in the rates of tracheostomy in trauma patients with acute respiratory failure. In a study of 17,523 subjects from the National Trauma Data Bank, for $24 \%$ of subjects $(n=4,146)$ who underwent tracheostomy, the mean tracheostomy rate across centers was 19.6 per 100 hospital admissions, but ranged from 0 to 59. Subject characteristics accounted for only $14 \%$ of the variance across centers. This study emphasized the need for well-conducted randomized trials to determine optimal indications for tracheostomy in adult trauma patients. ${ }^{26}$

\section{Complications of Tracheostomy}

Tracheostomy complications can be considered in 3 time frames: immediate, early, and late (Table 2). ${ }^{27,28}$ In the most recent prospective randomized tracheostomy trials, adverse events associated with tracheostomy were common, especially bleeding, but were not life-threatening. All clinicians who are credentialed to perform tracheostomy should be familiar with the proper methods of managing complications associated with tracheostomy. 


\section{TRACHEOSTOMY}

Table 2. Complications of Tracheostomy

\begin{tabular}{|c|c|c|}
\hline $\begin{array}{c}\text { Immediate } \\
\text { Complications }\end{array}$ & $\begin{array}{c}\text { Early } \\
\text { Complications }\end{array}$ & $\begin{array}{c}\text { Late } \\
\text { Complications }\end{array}$ \\
\hline Hemorrhage & Hemorrhage & Tracheal stenosis \\
\hline $\begin{array}{l}\text { Structure damage to } \\
\text { trachea }\end{array}$ & Tube displacement & Granulation tissue \\
\hline Failure of procedure & Pneumothorax & Tracheomalacia \\
\hline Aspiration event & Pneumomediastinum & Pneumonia \\
\hline Air embolism & $\begin{array}{l}\text { Subcutaneous } \\
\text { emphysema }\end{array}$ & Aspiration event \\
\hline Loss of airway & Stomal infection & Tracheoarterial fistula \\
\hline Death & Stomal ulceration & $\begin{array}{l}\text { Tracheoesophageal } \\
\text { fistula }\end{array}$ \\
\hline \multirow[t]{2}{*}{$\begin{array}{l}\text { Hypoxemia, } \\
\text { hypercarbia }\end{array}$} & $\begin{array}{l}\text { Accidental } \\
\text { decannulation }\end{array}$ & $\begin{array}{l}\text { Accidental } \\
\text { decannulation }\end{array}$ \\
\hline & Dysphagia & Dysphagia \\
\hline
\end{tabular}

\section{Outcomes of Tracheostomy}

Since the main indication for tracheostomy is in patients with acute respiratory failure requiring mechanical ventilation, it is no surprise that the mortality rates in tracheostomy patients are high. A recent review of the University Health System Consortium database analyzed 44,124 acute respiratory failure subjects, 4,776 (10.8\%) of whom underwent tracheostomy (Table 3). Tracheostomy subjects had higher rates of morbidity but lower rates of mortality $(20.6 \%)$ than non-tracheostomy subjects. Tracheostomy subjects were more resource-intensive to manage as evidenced by longer ICU and hospital stay, higher total hospital costs, and greater likelihood of being discharged to an in-patient facility (long-term care facility, skilled nursing facility, rehabilitation facility). ${ }^{29}$

A single-center study of hospital and long-term outcomes after tracheostomy for respiratory failure $(n=429)$ reported a hospital mortality rate of $19 \%$, with only $57 \%$ of survivors liberated from mechanical ventilation. At $100 \mathrm{~d}$, 6 months, $1 \mathrm{y}$, and $2 \mathrm{y}$ after discharge, 24\%, 30\%, 36\%, and $42 \%$ of hospital survivors had died, respectively. ${ }^{30} \mathrm{~A}$ review of mortality rates in tracheostomy subjects from recent clinical trials (Table 4) documents the high mortality rate in this patient population, with most studies reporting 1 -y mortality rates of $\sim 50 \%$.

\section{Timing of Tracheostomy}

Despite advantages of tracheostomy in the setting of prolonged mechanical ventilation, optimal timing for tracheostomy has remained controversial. ${ }^{37,38} \mathrm{~A}$ number of observational studies have documented considerable variability in tracheostomy timing. A consensus conference on artificial airways in patients receiving mechanical ventilation made the following recommendation: "The appropriate duration of translaryngeal intubation cannot be defined at present. Clinical consideration or complications may dictate changing the artificial airway to another route. However, no data exist that give adequate direction as to when it is routinely advisable to change from a translaryngeal intubation to a tracheostomy." ${ }^{39}$

A recent comprehensive review of the Project IMPACT database (109 ICUs) documented that tracheostomy placement occurred at a median of $9 \mathrm{~d}$ (interquartile range 5-14) after ICU admission. In a secondary analysis comparing surgical ICU subjects $(n=539)$ at Barnes-Jewish Hospital with subjects from 18 surgical ICUs in the Project IMPACT database, it was found that tracheostomy placement occurred more commonly in the Barnes-Jewish group $(54.2 \%$ vs $13.9 \%, P<.001)$. Furthermore, at each time point, the proportion of subjects ventilated via tracheos-

Table 3. Outcomes of Adult Subjects With Acute Respiratory Failure and With Versus Without Tracheostomy Cared for in Academic Medical Centers

\begin{tabular}{|c|c|c|c|c|}
\hline & $\begin{array}{l}\text { All Subjects } \\
(n=44,124)\end{array}$ & $\begin{array}{l}\text { Non-tracheostomy Subjects } \\
\qquad(n=39,348)\end{array}$ & $\begin{array}{l}\text { Tracheostomy Subjects } \\
\qquad(n=4,776)\end{array}$ & $P$ \\
\hline Complications, $n(\%)$ & $5,780(13.1)$ & $2,872(7.3)$ & $2,899(60.7)$ & $<.001$ \\
\hline Mortality, $n(\%)$ & $11,781(26.7)$ & $10,781(27.4)$ & 984 (20.6) & $<.001$ \\
\hline $\mathrm{ICU}$ stay, mean $\pm \mathrm{SD} \mathrm{d}$ & $8.5 \pm 10.5$ & $6.6 \pm 7.9$ & $24.3 \pm 20.7$ & $<.001$ \\
\hline Hospital stay, mean \pm SD d & $14.1 \pm 21.0$ & $11.3 \pm 19.8$ & $36.6 \pm 27.6$ & $<.001$ \\
\hline Total hospital costs, mean \pm SD $\$$ & $107,705 \pm 151,131$ & $86,118 \pm 107,771$ & $285,509 \pm 292,813$ & $<.001$ \\
\hline Discharge destination (survivors), $n(\%)$ & & & & $<.001$ \\
\hline Home (out-patient care) & $18,929(42.9)$ & $18,493(47.0)$ & $602(12.6)$ & \\
\hline Hospice & $1,014(2.3)$ & $944(2.4)$ & $72(1.5)$ & \\
\hline $\begin{array}{l}\text { In-patient setting (eg, acute care hospital, } \\
\text { rehabilitation, skilled nursing facility) }\end{array}$ & $23,959(54.3)$ & $19,753(50.2)$ & $4,069(85.2)$ & \\
\hline No data available & $221(0.5)$ & $157(0.4)$ & $33(0.7)$ & \\
\hline
\end{tabular}




\section{TRACHEOSTOMY}

Table 4. Outcomes Associated With Tracheostomy

\begin{tabular}{|c|c|c|c|c|c|c|}
\hline & $n$ & $\begin{array}{c}\text { ICU Mortality, } \\
n(\%)\end{array}$ & $\begin{array}{c}\text { Hospital or } \\
\text { 28/30/90-d Mortality, } \\
n(\%)\end{array}$ & $\begin{array}{l}1-y \text { or } 2-6-y \\
\text { Mortality, \% }\end{array}$ & $\begin{array}{c}\text { ICU stay, } \\
\text { Mean } \pm \text { SD d, } \\
\text { Median (IQR) }\end{array}$ & $\begin{array}{c}\text { Duration of } \\
\text { Mechanical Ventilation } \\
\text { Mean } \pm \text { SD d, } \\
\text { Median (IQR) }\end{array}$ \\
\hline Combes et $\mathrm{al}^{31}$ & 166 & $55 / 166(33)$ & $62 / 166(37)$ & & $41 \pm 27$ & $35 \pm 25$ \\
\hline Clec'h et al ${ }^{32}$ & 177 & $(27.68)$ & (42.94) & & $46(29-67)$ & $33(22-54)$ \\
\hline Rumbak et $\mathrm{al}^{33}$ & 120 & & 30-d mortality & & & \\
\hline $\begin{array}{l}\text { Early tracheostomy } \\
\quad(48 \mathrm{~h})\end{array}$ & & & $19 / 60(31.7)$ & & $4.8 \pm 1.4$ & $7.6 \pm 4.0$ \\
\hline $\begin{array}{l}\text { Late tracheostomy } \\
\quad(14-16 \mathrm{~d})\end{array}$ & & & $37 / 60(61.7)$ & & $16.2 \pm 3.8$ & $17.4 \pm 5.3$ \\
\hline Scales et $\mathrm{al}^{34}$ & 10,927 & & 90-d mortality & & & \\
\hline $\begin{array}{l}\text { Early tracheostomy } \\
\quad(<10 \mathrm{~d})\end{array}$ & 3,758 & & (34.8) & $\begin{array}{l}\text { 1-y mortality, } 46.5 ; \\
6-y \text { mortality, } 63.9\end{array}$ & & $14(10-26)$ \\
\hline $\begin{array}{l}\text { Late tracheostomy } \\
\quad(>10 \mathrm{~d})\end{array}$ & 7,169 & & $(36.9)$ & $\begin{array}{l}\text { 1-y mortality, } 49.8 ; \\
6-y \text { mortality, } 67.2\end{array}$ & & $30(22-45)$ \\
\hline Terragni et $\mathrm{al}^{35}$ & 419 & & 28-d mortality & & & \\
\hline $\begin{array}{l}\text { Early tracheostomy } \\
\quad(6-8 \mathrm{~d})\end{array}$ & & $108 / 209(52)$ & $108 / 209(52)$ & & & \\
\hline $\begin{array}{l}\text { Late tracheostomy } \\
\qquad(13-15 \mathrm{~d})\end{array}$ & & $128 / 210(61)$ & $128 / 210(61)$ & & & \\
\hline Young et al ${ }^{36}$ & 455 & & 30-d mortality & & & \\
\hline $\begin{array}{l}\text { Early tracheostomy } \\
\qquad(\leq 4 \mathrm{~d})\end{array}$ & & $113 / 448(29.7)$ & (30.8) & $\begin{array}{l}\text { 1-y mortality, } 45.9 ; \\
2-y \text { mortality, } 51.0\end{array}$ & 13.0 & $13.6 \pm 12.0$ \\
\hline $\begin{array}{l}\text { Late tracheostomy } \\
\qquad(>10 \mathrm{~d})\end{array}$ & & $132 / 445(29.7)$ & $(31.5)$ & $\begin{array}{l}\text { 1-y mortality, } 49.0 \\
2 \text {-y mortality, } 53.7\end{array}$ & 13.1 & $15.2 \pm 14.4$ \\
\hline
\end{tabular}

tomy was significantly greater in the Barnes-Jewish Hospital group (Fig. 1)..$^{40}$

The question of early versus late tracheostomy is complex and requires a 2-part solution: (1) we must predict which patients will require prolonged ventilation, and (2) we must make a decision about when the tracheostomy should be performed. If prediction of prolonged ventilation is imperfect, then a strategy of early tracheostomy will lead to some patients undergoing tracheostomy unnecessarily, whereas a strategy of late tracheostomy will result in other patients facing unnecessarily prolonged exposure to translaryngeal endotracheal tube requirement and potentially prolonged weaning from mechanical ventilation.

The definition of early tracheostomy differs between studies. Of the papers surveyed from the past $10 \mathrm{y}$, early was generally defined as within 3-10 d of mechanical ventilation, whereas late was variously defined as any time outside the early period, within 7-14 d, 14-28 d, or $>28 \mathrm{~d}$ after initiation of mechanical ventilation.

\section{Observational Studies}

A number of small cohort observational studies examined the issues of optimal tracheostomy timing. A retro- spective study of 531 mechanically ventilated subjects in a mixed medical/surgical ICU determined that earlier timing of tracheostomy correlated with shorter time on mechanical ventilation and shorter ICU and hospital stay, but was not associated with hospital mortality. ${ }^{41}$ A single-institution study compared early (within $5 \mathrm{~d}$ of intubation, $n=110$ ) versus late (after $5 \mathrm{~d}$ of intubation, $n=418$ ) tracheostomy outcomes and found that earlier tracheostomy was associated with a shorter duration of mechanical ventilation and shorter ICU stay, with no differences in hospital or ICU mortality. ${ }^{42}$ A retrospective single-institution study compared early ( $\leq 7 \mathrm{~d}, n=81)$ versus late $(>7 \mathrm{~d}, n=104)$ tracheostomy outcomes in a surgical ICU and found that early tracheostomy was associated with decreased VAP, ventilator days, and hospital and ICU stay, but no differences in the rates of ARDS or lung injury. ${ }^{43}$

Additional small cohort studies documented variable outcome differences based on tracheostomy timing. ${ }^{44-46}$ The differences in study population and timing make it difficult to draw definitive conclusions for the benefit of early tracheostomy and also what defines early versus late tracheostomy. However, all of these studies demonstrated either benefit or null effect for early tracheostomy, and none demonstrated detrimental effects. 


\section{TRACHEOSTOMY}

A
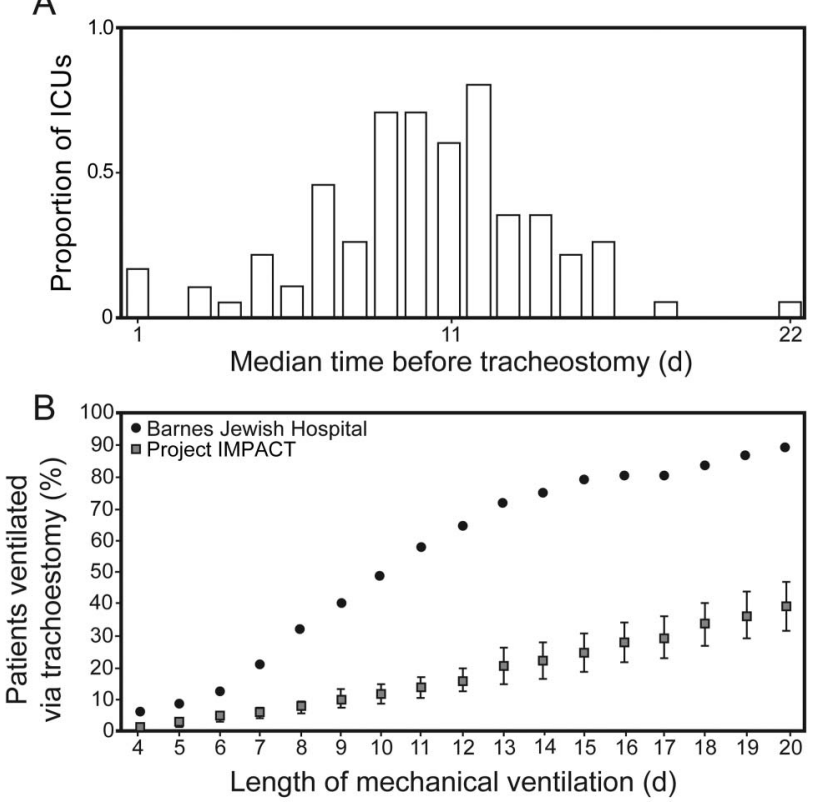

Fig. 1. A: Tracheostomy timing in Project IMPACT surgical ICUs. B: Tracheostomy utilization in Project IMPACT surgical ICUs and Barnes-Jewish Hospital surgical ICUs. Adapted from Reference 40.

\section{Meta-Analysis (4 Studies)}

A systematic review and meta-analysis of studies of the timing (early vs late) of tracheostomy in adult subjects undergoing mechanical ventilation in 2005 included 4 randomized controlled trials (RCTs) ${ }^{33,47-49}$ and documented no difference in mortality (relative risk $0.79,95 \%$ CI $0.45-$ 1.39) or hospital-acquired pneumonia (relative risk 0.90 , 95\% CI $0.66-1.21$ ), but early tracheostomy was associated with significantly decreased duration of mechanical ventilation and shorter ICU stay. ${ }^{50}$ There were major differences in the specific tracheostomy timing (early vs late) and the patient populations (medical critically ill, surgical critically ill, burn injury, head injury subjects) in these 4 studies, and no standard ventilator weaning protocol was used, making ventilator duration and ICU stay outcomes vulnerable to clinical practices in these ICUs.

\section{Large Retrospective Cohort Study}

In 2008, a large $(n=10,927)$ retrospective analysis from Ontario compared mechanically ventilated subjects who underwent early (prior to $10 \mathrm{~d}, n=3,758$, one third of study cohort) versus late ( $>10 \mathrm{~d}, n=7,169$, two thirds of study cohort) tracheostomy. Early tracheostomy had lower unadjusted 90 -d $(34.8 \%$ vs $36.9 \%, P=.032), 1-\mathrm{y}$ (46.5\% vs $49.8 \%, P=.001)$, and study $(63.9 \%$ vs $67.2 \%$, $P<.001)$ mortality versus late tracheostomy. Multivari- able analyses (tracheostomy as a time-dependent variable) determined that each additional 1-d delay was associated with increased mortality (hazard ratio 1.008 , 95\% CI 1.0041.012), equivalent to an increase in $90-\mathrm{d}$ mortality from $36.2 \%$ to $37.6 \%$ per week of delay (relative risk increase $3.9 \%$ ). This study identified a small benefit for $90-\mathrm{d}$ and $1-y$ mortality in the early tracheostomy cohort, with 71 as the number of subjects needed to treat to save one life per week of delay. ${ }^{34}$

\section{Early Versus Late Tracheotomy Study: Italian Multi-Center Prospective Randomized Trial}

This trial was performed in 12 Italian ICUs from June 2004 to June 2008 and enrolled 600 adult subjects without pneumonia (estimated by a Clinical Pulmonary Infection Score [CPIS] of $<6$ ) who had been ventilated for $24 \mathrm{~h}$, had a Simplified Acute Physiology Score II between 35 and 65, and had a Sequential Organ Failure Assessment score of 5 or greater. ${ }^{35}$ These subjects were monitored for $48 \mathrm{~h}$, and those with worsening respiratory failure, unchanged or worse Sequential Organ Failure Assessment score, and no pneumonia were then randomized to early (after 6-8 d of laryngeal intubation, $n=209$ ) or late (after $13-15 \mathrm{~d}$ of laryngeal intubation, $n=210$ ) tracheostomy.

The primary outcome measure was VAP, with secondary end points of 28-d assessment of ventilator-free days, ICU-free days, and survival. The presence of VAP was defined using the simplified CPIS, with a CPIS score $>6$ indicative of VAP, calculated at study entry, at randomization, and every $72 \mathrm{~h}$ until study day $28 .{ }^{51}$

This study included both medical and surgical subjects with no difference in early ( $40 \%$ medical, $8 \%$ scheduled surgery, $41 \%$ unscheduled surgery, $11 \%$ trauma) versus late (36\% medical, $10 \%$ scheduled surgery, $45 \%$ unscheduled surgery, $9 \%$ trauma) tracheostomy groups. Many of the randomized subjects did not undergo tracheostomy ( $31 \%$ early and $43 \%$ late) related to proximity to either extubation or death. In the early group, 145 of 209 subjects (69\%) underwent tracheostomy compared with 119 of 210 subjects (57\%) in the late group.

All tracheostomies were performed bedside using percutaneous techniques (Griggs technique ${ }^{52}$ in $72 \%$ early and $73 \%$ late, PercuTwist technique ${ }^{53}$ in $25 \%$ early and $22 \%$ late groups). Adverse events occurred in 39\% of both early and late tracheostomy groups, with postoperative stomal inflammation most common, occurring in $15 \%$ of each group.

VAP (defined by CPIS) developed in $30(14 \%)$ of early versus $44(21 \%)$ of late tracheostomy patients $(P=.07)$. Although the number of ICU-free and ventilator-free days was higher in the early tracheostomy group, the long-term outcome end point of 28-d survival (154 of 209 [74\%] in the early group vs 144 of 210 [68\%] in the late group, $P=.25)$ did not differ. 


\section{TRACHEOSTOMY}

The use of CPIS for VAP diagnosis is a significant limitation in this study. The diagnostic accuracy of CPIS is limited in surgical, trauma, and burn patients, as CPIS was unable to differentiate VAP from systemic inflammatory response syndrome. ${ }^{54}$ Furthermore, the utility of the modified CPIS to diagnose VAP was assessed in 740 subjects enrolled in a multi-center randomized trial, and no CPIS threshold was clinically useful (receiver operating characteristic area under the curve $0.47,95 \%$ CI $0.42-0.53) .55$

The authors concluded that early tracheostomy (performed after 6-8 d of endotracheal intubation) did not result in significant reduction in the incidence of VAP compared with late tracheostomy (performed after 13-15 d of endotracheal intubation) and was associated with an adverse event related to the tracheostomy procedure in more than one third of subjects. These data suggest that tracheostomy should not be performed earlier than after $13-15 \mathrm{~d}$ of intubation.

\section{Meta-Analysis (7 Studies)}

Seven trials with 1,044 subjects were analyzed, including 4 additional trials from the 2005 meta-analysis. ${ }^{47,56-58}$ Early tracheostomy was not associated with reduced short-term mortality (relative risk $0.86,95 \% \mathrm{CI} 0.65-1.13$ ), long-term mortality (relative risk $0.84,95 \%$ CI $0.68-1.04$ ), or VAP (relative risk $0.94,95 \%$ CI $0.77-1.15$ ) in critically ill subjects. The timing of the tracheotomy was not associated with changes in duration of mechanical ventilation, ICU or hospital stay, or complications. The authors of this meta-analysis suggested that the timing of the tracheotomy did not significantly alter clinical outcomes in critically ill subjects. ${ }^{59}$

\section{Meta-Analysis (4 Studies)}

In the Cochrane meta-analysis published in 2012, of the published randomized or quasi-randomized studies comparing early (2-10 d after intubation) versus late $(>10 \mathrm{~d}$ after intubation) tracheostomy in the databases queried, only 4 were deemed eligible for meta-analysis. ${ }^{33,35,56,60}$ No mortality difference was found, and one of the 4 studies found a decrease in ventilator time for the early tracheostomy group. ${ }^{61}$

\section{TracMan: Largest Multi-Center Prospective Randomized Trial (United Kingdom)}

The TracMan trial ${ }^{36}$ was an open multi-center RCT conducted from 2004 through 2011 in 70 adult general and 2 cardiothoracic ICUs in 13 university and 59 non-university hospitals in the United Kingdom. Of 1,032 eligible patients, 909 subjects were enrolled. Inclusion criteria were mechanically ventilated subjects in adult ICUs who were identified by the treating clinician in the first $4 \mathrm{~d}$ after admission as likely to require at least an additional $7 \mathrm{~d}$ of ventilator support. Exclusion criteria included those in whom immediate tracheostomy was needed or was contraindicated due to anatomical or other reasons or those with respiratory failure due to chronic neurological diseases since study centers indicated those patients receive early tracheostomies.

Subjects were randomized to early (within $4 \mathrm{~d}$ after intubation, $n=455$ ) or late (after $10 \mathrm{~d}$ if still indicated, $n=454)$ tracheostomy. Most subjects were medical ( $n=712,79.2 \%$ of study cohort), with respiratory failure as the primary admission diagnosis $(n=515,59.5 \%)$.

Interestingly, in the early tracheostomy group, $91.9 \%$ of subjects received tracheostomy as planned; in contrast, in the late tracheostomy group, only $45.5 \%$ of subjects required tracheostomy. Many subjects in the late tracheostomy group were liberated from mechanical ventilation without requiring tracheostomy. Details of the tracheostomy procedure in this study revealed that $90 \%$ of the tracheostomies were performed by the percutaneous technique, with $88.7 \%$ performed in the ICU at the bedside, and the majority ( $n=426,77.3 \%)$ were performed by the single tapered dilator technique. Complications related to tracheostomy occurred in $6.3 \%$ of subjects, with the majority $(3.1 \%)$ related to bleeding and no difference between the early $(5.5 \%)$ and late $(7.8 \%)$ groups.

No differences in 30 -d mortality (30.8\% early vs $31.5 \%$ late), 2-y mortality (51.0\% early vs $53.7 \%$ late), or median ICU stay in survivors (13.0 d early vs $13.1 \mathrm{~d}$ late) were identified. No difference in hospital stay or duration of mechanical ventilation was identified. Early tracheostomy was associated with significantly decreased sedation use. In survivors at $30 \mathrm{~d}$ after randomization, the median number of days on which any sedatives were received was 5 (interquartile range 3-9) in the early group and 8 (interquartile range $4-12)$ in the late group $(P<.001)$, with a mean difference between the groups of $2.4 \mathrm{~d}(95 \% \mathrm{CI}$ 1.6-3.6). No specific assessment of VAP was performed in this study, but antibiotic use up to $30 \mathrm{~d}$ after randomization was the same in both groups.

The authors concluded that "for patients breathing with the aid of mechanical ventilation treated in adult ICUs in the United Kingdom, tracheostomy within $4 \mathrm{~d}$ of ICU admission was not associated with an improvement in 30-d mortality or other important secondary outcome." This study also documented that the ability of clinicians to predict which patients required extended ventilator support was limited. At the study's presentation at the 29th International Symposium of Intensive Care and Emergency Medicine, the lead author stated, "If you had 100 patients requiring tracheostomy, doing it early results in $2.4 \mathrm{~d}$ less sedation overall, but you would perform 48 more, with 3 more procedural complications and no effect on mortality or ICU stay." 


\section{TRACHEOSTOMY}

\section{Optimal Timing of Tracheostomy Based on Recent Randomized Controlled Trials}

These 2 recent randomized trials (Italian multi-center trial $^{35}$ and TracMan United Kingdom multi-center trial ${ }^{36}$ ) have consistent findings that earlier tracheostomy was not associated with improved survival and that clinicians cannot accurately predict which patients will require prolonged mechanical ventilation. Based on the evidence to date, it is reasonable to wait at least $10 \mathrm{~d}$ to be certain that a patient has an ongoing need for mechanical ventilation or assistance with pulmonary toilet before consideration of tracheostomy.

\section{Limitations of Tracheostomy Timing Studies}

There are a significant number of limitations of the recent studies regarding tracheostomy timing that have been completed to date, including the following:

- Small number of trauma and surgical patients

- Different outcome measures: all-cause mortality versus VAP versus ICU/ventilator-free days

- VAP not measured in the TracMan trial

- VAP definition problematic in the Italian trial (CPIS $>6$ not valid in surgical and trauma patients)

- Control for weaning and sedative/analgesic use in Italian trial, but not in TracMan

- No standardization of tracheostomy technique (open or percutaneous in TracMan, Griggs vs PercuTwist in Italian multi-center trial)

- No large United States RCT to date

\section{Charges and Compensation for Tracheostomy}

At present, there is significant reimbursement for early tracheostomy tube placement. Medicare and some commercial insurers provide high reimbursement to hospitals for patients who undergo early (within $4 \mathrm{~d}$ ) tracheostomy. A patient who undergoes $96 \mathrm{~h}$ of mechanical ventilation can be recoded to diagnosis-related group (in-patient payment bundle) 003 or 004 if a tracheostomy is performed within this time period. These are 2 of the most highly reimbursed diagnosis-related groups (Table 5). ${ }^{62}$ An unintended consequence of this current compensation method is the creation of a significant financial incentive for earlier tracheostomy procedures. All insurance carriers also pay the physician for performing the procedure, and physician charges are not included in the diagnosis-related group payments for the in-patient hospitalization. There-
Table 5. DRG 003 or 004 for Tracheostomy Procedure

\begin{tabular}{|c|c|c|}
\hline DRG & MS-DRG Title & $\begin{array}{c}\text { Fiscal Year } 2013 \\
\text { Base Payment Rates }\end{array}$ \\
\hline 003 & $\begin{array}{l}\text { Tracheostomy with mechanical ventilation } \\
96+\mathrm{h} \text { WITH major operating } \\
\text { room procedure }\end{array}$ & $\$ 101,516.38$ \\
\hline 004 & $\begin{array}{l}\text { Tracheostomy with mechanical ventilation } \\
96+\mathrm{h} \text { WITHOUT major operating } \\
\text { room procedure }\end{array}$ & $\$ 62,178.06$ \\
\hline 001 & $\begin{array}{l}\text { Heart transplant or implant of heart assist } \\
\text { system WITH major complications and } \\
\text { comorbidities }\end{array}$ & $\$ 147,512.68$ \\
\hline 002 & $\begin{array}{l}\text { Heart transplant or implant of heart assist } \\
\text { system WITHOUT major complications } \\
\text { and comorbidities }\end{array}$ & $\$ 79,759.38$ \\
\hline \multicolumn{3}{|c|}{$\begin{array}{l}\text { A patient who undergoes } 96 \mathrm{~h} \text { of mechanical ventilation can be recoded to diagnosis-related } \\
\text { group (DRG) } 003 \text { or } 004 \text { if tracheostomy is performed. These are } 2 \text { of the most highly } \\
\text { reimbursed diagnosis-related groups, similar to hospital payments received for heart transplant. } \\
\text { From Reference } 62 \text {. } \\
\text { MS = Medicare \& Medicaid Services }\end{array}$} \\
\hline
\end{tabular}

fore, providers who perform tracheostomy have an additional incentive to perform tracheostomies.

In the retrospective review of the North Carolina Hospital discharge database that documented a significant increase in tracheostomy placement between 1993 and 2002, tracheostomy charges were examined. Although subjects on prolonged mechanical ventilation with tracheostomies represented only $7 \%$ of all who required mechanical ventilation, their total charges during the study period were $\$ 1.74$ billion, comprising $22 \%$ of all mechanically ventilated patient charges. ${ }^{21}$

As long as hospitals are reimbursed using this diagnosis-related group system, it would seem prudent to revise the reimbursement strategies for patients facing potentially prolonged mechanical ventilation to better align financial incentives with the best clinical evidence. The expected effects of the Affordable Care Act and value-based purchasing will likely result in less payment for procedures and more payment aligned with quality of care.

\section{Patients Who Would Benefit From Early Tracheostomy?}

There are other patient groups who may benefit from early tracheostomy, particularly those who require little or no assistance from mechanical ventilation yet still require airway protection or pulmonary toilet. Trauma and neurologic damage from stroke, head injury, and spinal cord injury (SCI) represent a subset of patients for whom the benefits of early tracheostomy have been specifically investigated. For these studies, 7-8 d was a relatively consistent cutoff to define early versus late tracheostomy. 


\section{TRACHEOSTOMY}

\section{Trauma}

The sole prospective randomized trial within the past $10 \mathrm{y}$ examining tracheostomy timing in trauma patients was performed by Barquist et al, ${ }^{56}$ who compared trauma subjects who received a tracheostomy within $8 \mathrm{~d}$ of intubation versus subjects whose tracheostomies were delayed until after $28 \mathrm{~d}$ in a single-center trial. No differences in ventilator-free or ICU-free days at hospital days 20 and 30 and no differences in rates of VAP and hospital mortality were identified. This study was halted after the first interim analysis, with only 60 enrolled subjects. ${ }^{56}$

Retrospective cohort studies demonstrated larger benefits to earlier tracheostomy. A single-center 5-y study of trauma subjects who received tracheostomy compared 29 subjects with early tracheostomy (within $7 \mathrm{~d}$ ) to 107 patients with late tracheostomy ( $>7 \mathrm{~d}$ ) and found that early tracheostomy in trauma ICU patients was associated with shorter duration of mechanical ventilation and ICU stay, but no difference in hospital stay or ICU and hospital mortality. ${ }^{63}$

Using the Pennsylvania Statewide Trauma Registry, a multi-institutional retrospective cohort study examined 685 trauma subjects who received tracheostomy. This study further stratified trauma subjects into low and high probability of survival (based on the Trauma Score-Injury Severity Score) and stratified tracheostomy timing into early $(0-3 \mathrm{~d})$, early intermediate (4-7 d), late intermediate (8-12 d), and late $(>12 \mathrm{~d})$ post-injury. Early tracheostomy was associated with decreased ICU stay, hospital stay, total ventilator days, and rates of pneumonia in trauma patients with a high probability of survival. Interestingly, in the population of subjects characterized with a low probability of survival, early tracheostomy was unexpectedly associated with a significantly higher mortality. ${ }^{64}$ Given the disparity in findings between prospective and retrospective trials in this population, more prospective randomized trials are required.

\section{Traumatic Brain Injury}

Patients with traumatic brain injury (TBI) are another population of patients for whom tracheostomy timing has been evaluated. A prospective cohort study compared 31 subjects with isolated TBI who received a tracheostomy at $\mathrm{d} 5$ or 6 versus 31 similar TBI subjects who did not undergo tracheostomy and found that tracheostomy was associated with decreased overall ventilator time, decreased ventilator days after diagnosis of VAP, and a shorter period to extubation, but no differences in rates of pneumonia or hospital mortality. ${ }^{49} \mathrm{~A}$ retrospective cohort study compared 27 TBI subjects who received early tracheostomy $(<7 \mathrm{~d}$ of intubation) versus 28 TBI subjects with late tracheostomy ( $>7 \mathrm{~d}$ of intubation) and found that early tracheostomy was associated with decreased ICU stay, but had no effect on hospital mortality, hospital stay, ventilator days, rates of VAP, or hospital cost. ${ }^{65}$
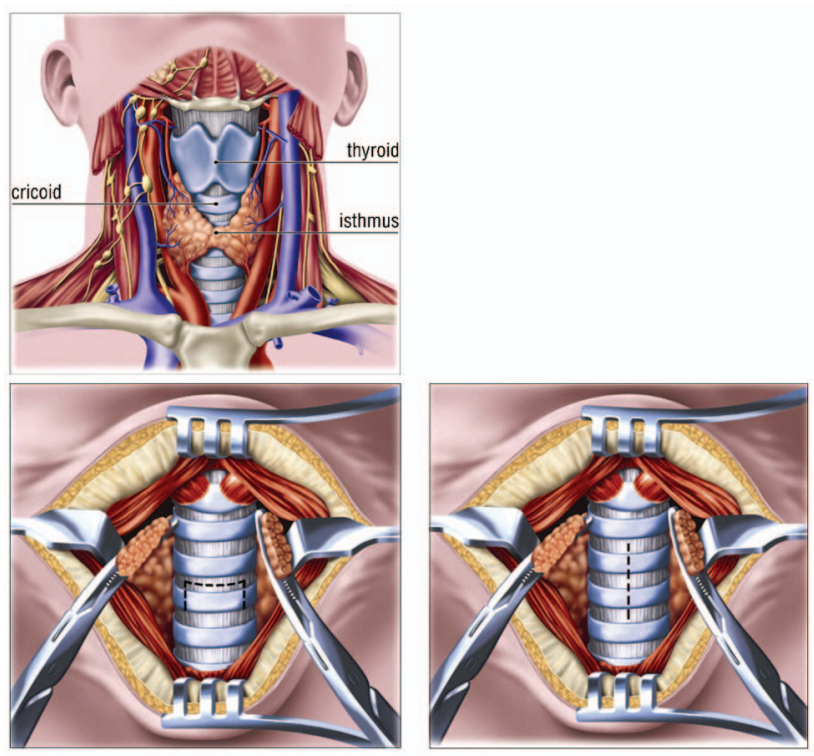

Fig. 2. Surgical open tracheostomy. This requires a $3-\mathrm{cm}$ vertical skin incision initiated below the inferior cricoid cartilage. The strap muscles are retracted laterally. The thyroid isthmus is retracted either superiorly or inferiorly or divided. An incision is created in the anterior trachea at the first or second tracheal rings. A sideways " $\mathrm{H}$ " incision at the level of the second tracheal ring is ideal and provides an open-book exposure without resection. From Reference 22, with permission.

A small retrospective study compared 11 TBI subjects with early tracheostomy (within $8 \mathrm{~d}$ ) versus 17 subjects with late tracheostomy (after $8 \mathrm{~d}$ ) and found a decrease in 28-d mortality, but no differences in ICU mortality, ICU-free days, or ventilator-free days. ${ }^{66}$ The largest retrospective cohort study compared 1,577 TBI subjects with one other organ system injury who received early tracheostomy (within $7 \mathrm{~d}$ ) versus 1,527 TBI subjects who received late tracheostomy (after $7 \mathrm{~d}$ ) and reported decreased hospital and ICU stay; decreased rates of adverse pulmonary, cardiac, infectious, and neurologic events; and improved independence at outcome with early tracheostomy, but also found increased hospital mortality. ${ }^{67}$ Similar to trauma patients, retrospective studies report that early tracheostomy (within 7-8 d) in TBI patients is associated with some improved outcomes compared with delayed tracheostomy, but no large prospective randomized trials have yet validated these findings.

\section{Spinal Cord Injury}

Recent studies of tracheostomy timing in patients with SCI show the same trend toward benefit for early tracheostomy as in trauma and TBI patients. A retrospective cohort study compared 71 SCI subjects with early tracheostomy (within $7 \mathrm{~d}$ ) with 81 similar subjects who received late tracheostomy (after $7 \mathrm{~d}$ ) and found decreased ICU days, ICU days after tracheostomy, ventilator days, and 


\section{TRACHEOSTOMY}
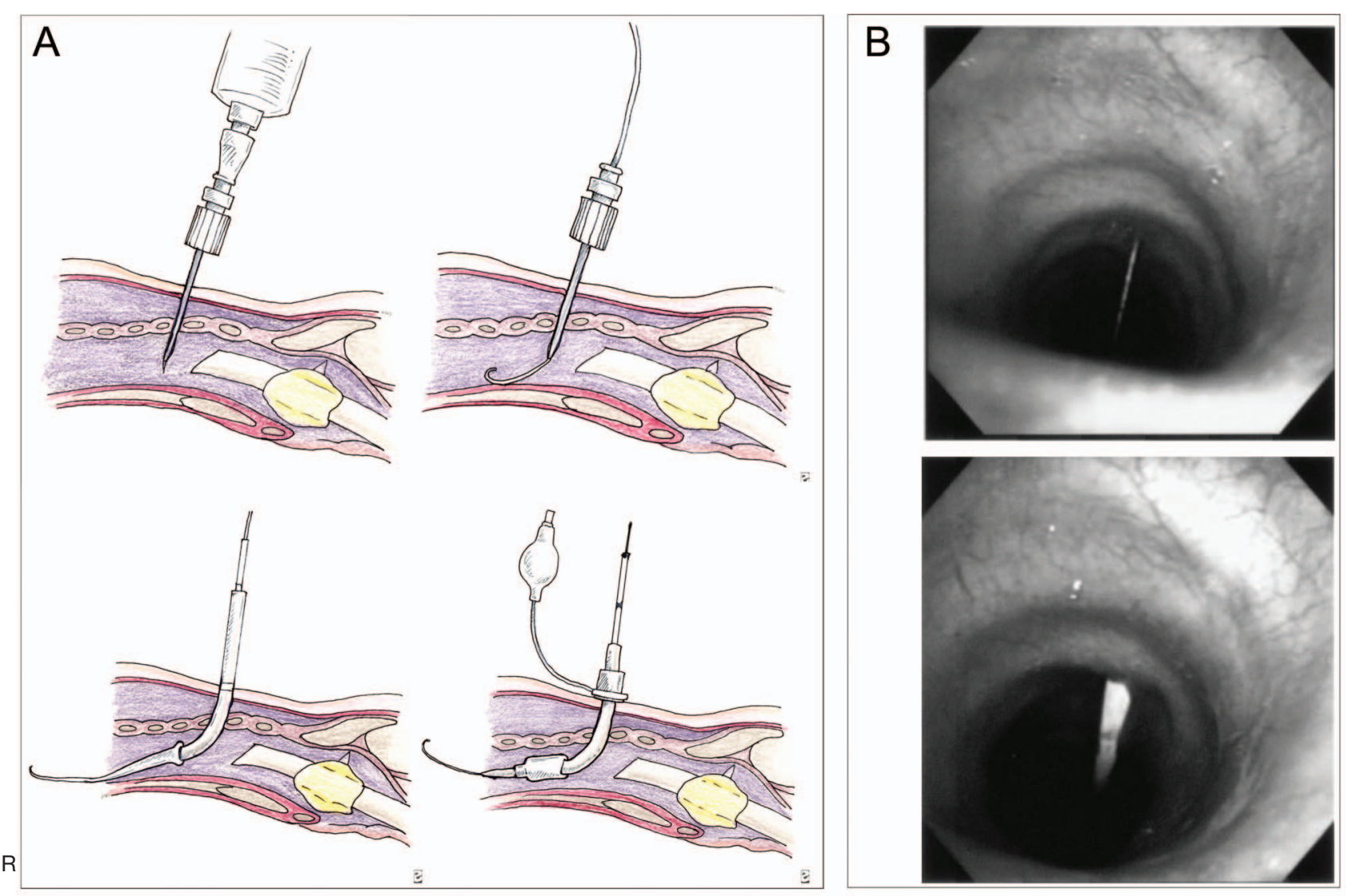

Fig. 3. Percutaneous dilatational tracheostomy (PDT) should be performed with flexible bronchoscopy guidance to visualize the anterior entry site of the needle, to avoid posterior tracheal injury, and to ensure that the guide wire and dilator are advanced distally. The single graded dilator technique is optimal. Advantages of PDT include (1) time required for bedside PDT is shorter than for open tracheostomy, (2) elimination of scheduling difficulty associated with operating room and anesthesiology for ICU patients, (3) PDT expedites performance of the procedure because critically ill patients who would require intensive monitoring to and from the operating room need not be transported; and (4) cost of performing PDT is roughly half that of open surgical tracheostomy due to the savings in operating room charges and anesthesiology fees. A: From Reference 73, with permission. B: From Reference 74.

ventilator days after tracheostomy in the early tracheostomy cohort, but no differences in hospital mortality and rates of VAP were identified. ${ }^{68}$ Ganuza et al ${ }^{69}$ retrospectively compared 101 SCI subjects with early tracheostomy ( $<7 \mathrm{~d}$ ) with 114 subjects with late tracheostomy ( $\geq 7 \mathrm{~d})$ and found decreased ventilator days, ICU days, and rates of tracheal stenosis, but no differences in rates of pneumonia, stomal cellulitis, or hospital mortality. As with other specialized patient populations, large prospective randomized trials are warranted in this area.

\section{Neurosurgical Patients}

A retrospective single-institution study of 125 subjects divided patients into 2 groups based on tracheostomy timing: early group within $10 \mathrm{~d}$ of mechanical ventilation $(n=39)$ versus late group after $10 \mathrm{~d}$ of mechanical ventilation $(n=86)$. Early tracheostomy reduced the mechanical ventilation duration $(11.4 \pm 5.6$ vs $21.5 \pm 15.5 \mathrm{~d}, P<.001)$, ICU stay $(19.9 \pm 10.6$ vs $31.1 \pm 18.2 \mathrm{~d}, P<.001)$, and incidence of
VAP $(23 \%$ vs $44 \%, P<.05)$ in critically ill neurosurgical subjects. However, early tracheostomy did not reduce either ICU or hospital mortality. ${ }^{70}$

\section{Mechanically Ventilated Patients With COPD}

Patients with COPD are at a particularly high risk for prolonged mechanical ventilation and VAP. Studies to evaluate early versus late tracheostomy in this patient population are needed. A single-institution trial (identifier NCT01021202, entitled "Timing of dilation tracheostomy in mechanically ventilated chronic obstructive pulmonary disease (COPD) patients") is ongoing in Hamburg, Germany, randomizing to early $(<72 \mathrm{~h}$ of mechanical ventilation) versus late $(>10 \mathrm{~d}$ of mechanical ventilation) tracheostomy. ${ }^{71}$

\section{Tracheostomy Technique}

Both open surgical tracheostomy (Fig. 2) and percutaneous tracheostomy (Fig. 3) are methods used to perform 


\section{TRACHEOSTOMY}

Table 6. Indications and Contraindications to PDT

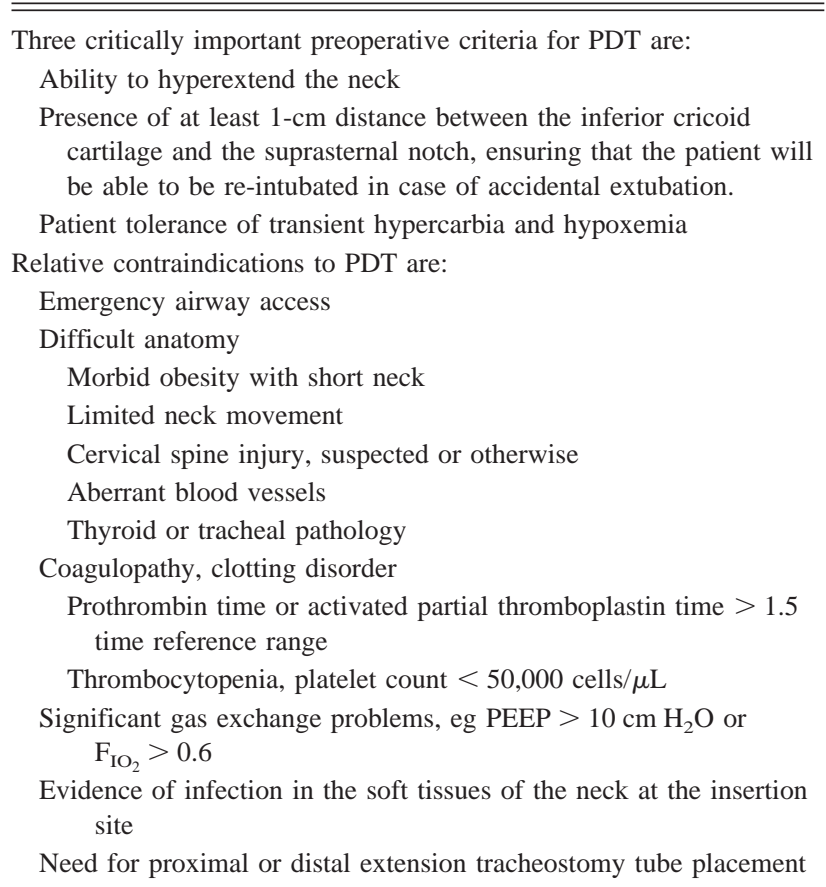

PDT $=$ percutaneous dilational tracheostomy

tracheostomy in select individuals. Some patients may require open surgical tracheostomy because of an inability to perform percutaneous tracheostomy due to anatomic or other patient-related issues. It is important to assess all potential issues to determine whether open surgical versus percutaneous tracheostomy should be performed in any patient who requires tracheostomy. Patient selection is a significant factor during the consideration of whether to perform percutaneous or surgical tracheostomy, and few of the studies directly comparing surgical and percutaneous tracheostomy address this issue. Contraindications to percutaneous tracheostomy are listed in Table 6.

\section{Open Surgical Versus Percutaneous Tracheostomy}

In most adult ICU patients requiring elective tracheostomy and without contraindications to percutaneous tracheostomy, it has been suggested that percutaneous dilatational tracheostomy (PDT) should be considered the procedure of choice. In a systematic review and metaanalysis of 17 RCTs involving 1,212 subjects, PDT performed in the ICU was associated with reduced wound infection (odds ratio [OR] 0.28, 95\% CI 0.16-0.49, $P<.001)$ and no difference in bleeding or major periprocedural and long-term complications. ${ }^{72}$ In another metaanalysis comparison of open versus percutaneous tracheostomy including 15 RCTs and nearly 1,000 subjects, there

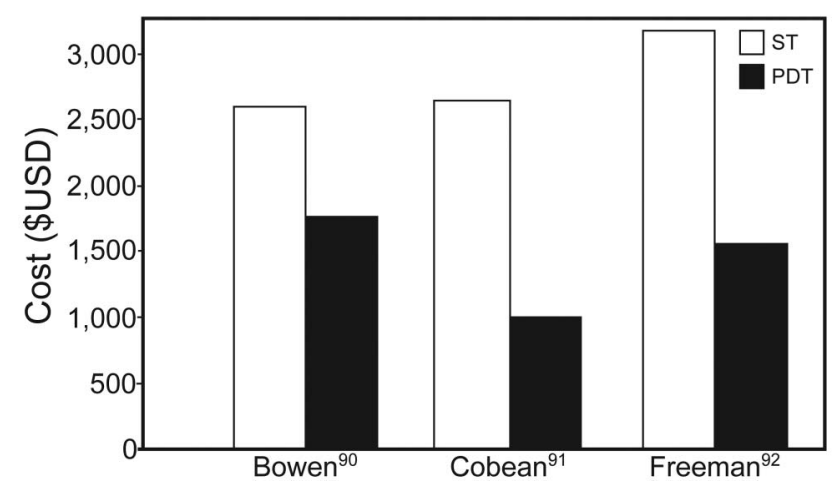

Fig. 4. Cost difference of percutaneous dilatational tracheostomy (PDT) vs surgical tracheostomy (ST). Courtesy Cook Medical.

were significantly fewer complications in the percutaneous group for wound infection and unfavorable scarring and no significant difference for complications of false passage, minor or major hemorrhage, subglottic stenosis, death, and overall complications. Importantly, percutaneous tracheostomy was associated with a higher rate of decannulation/obstruction (OR 2.79, 95\% CI 1.29-6.03). Percutaneous tracheostomy case length was shorter and associated with reduced costs (\$456 less) compared with open surgical tracheostomy (Fig. 4). ${ }^{75}$ The preponderance of evidence confirms that percutaneous tracheostomy is as safe as surgical tracheostomy and is associated with decreased procedural time and cost.

\section{Types of Percutaneous Tracheostomy}

A number of techniques have been developed for percutaneous tracheostomy (Table 7). PDT should be considered the preferred technique for this intervention in the appropriate selected individual.

A systematic review comparing different PDT techniques in critically ill adult patients examined data from 1,130 subjects in 13 randomized trials. Multiple dilators, singlestep dilatation, guide wire dilating forceps, rotational dilation, retrograde tracheostomy, and balloon dilation techniques were all performed bedside in the ICU. The different techniques and devices appeared largely equivalent, with the exception of retrograde tracheostomy, which was associated with more severe complications and more frequent need of conversion to other techniques compared with guide wire dilating forceps and single-step dilatation techniques. The single-step dilatation technique was associated with fewer failures compared with rotational dilation and fewer mild complications compared with balloon dilation and guide wire dilating forceps (all $P<.05$ ). Among the 6 analyzed techniques, the single-step dilatation technique appeared the most reliable in terms of safety and success rate. However, the number of available ran- 


\section{TRACHEOSTOMY}

Table 7. Specific Techniques for Percutaneous Tracheostomy Procedure

\begin{tabular}{lll}
\hline \hline \multicolumn{1}{c}{ Methodology } & Year & \\
\hline Sequential dilators, Ciaglia & 1985 & Multistep dilation with sequential dilators, antegrade \\
Dilating forceps, Griggs & 1990 & Dilation with specific forceps, antegrade \\
Translaryngeal tracheostomy, Fantoni & 1997 & Retrograde passage, specific cannula acts as dilator and tracheostomy tube \\
Single-step dilator, Ciaglia Blue Rhino & 1999 & Single-step dilation with curved dilator and loading dilator, antegrade \\
Dilating screw, Frova and Quintel ${ }^{53}$ & 2002 & Self-trapping screw, antegrade \\
T-Dagger, Ambesh & 2005 & Single-step dilation with curved T-shaped dilator, elliptical in cross section, antegrade \\
Balloon-facilitated dilational tracheostomy, & 2005 & Single-step dilation with balloon and loading dilator assembly, antegrade \\
$\quad$ Ciaglia Blue Dolphin & & \\
\hline
\end{tabular}
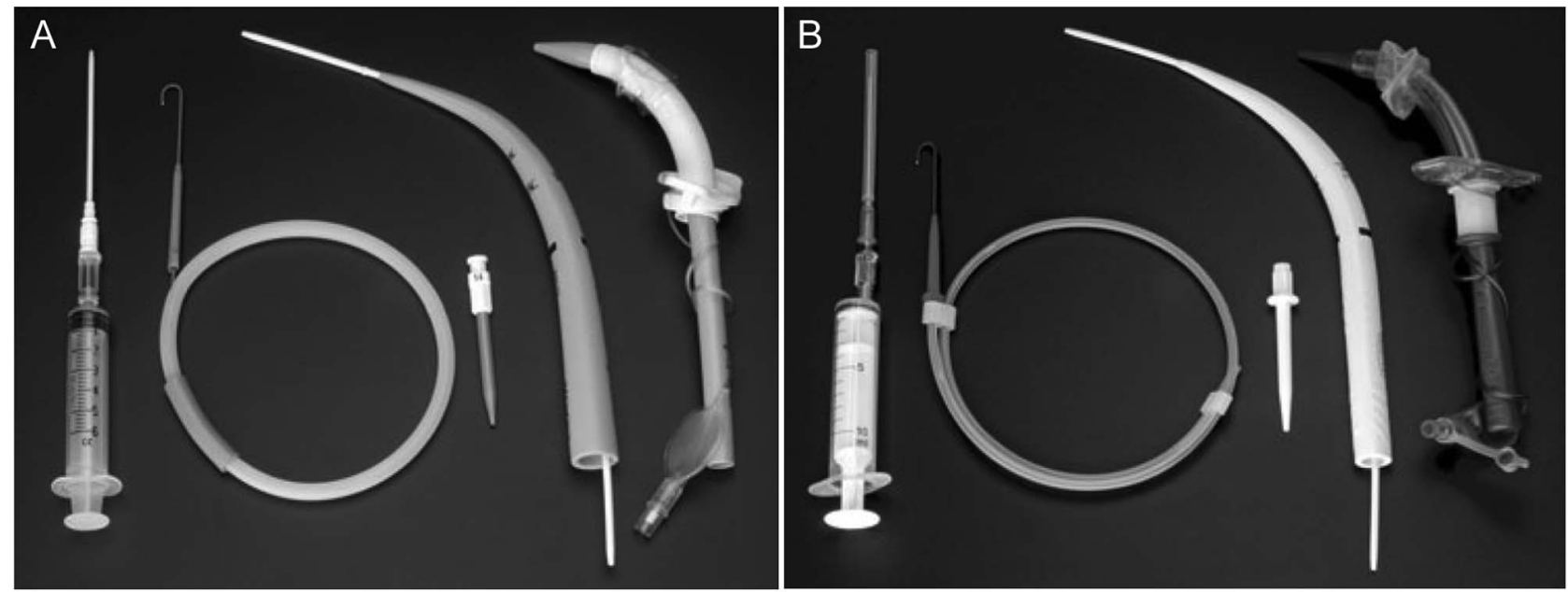

Fig. 5. Comparison of 2 single tapered dilator percutaneous tracheostomy sets. A: Ciaglia Blue Rhino. B: Portex ULTRAperc (White Rhino). From Reference 77, with permission.

domized trials was insufficient to confidently assess the best PDT technique. ${ }^{76}$

\section{Comparison of 2 Single Tapered Dilator Percutaneous Dilatational Tracheostomy Sets}

Two single tapered dilator percutaneous tracheostomy sets are in common use: the Ciaglia Blue Rhino (Cook Medical, Bloomington, Indiana) and Portex ULTRAperc (Smiths Medical, Dublin, Ohio) kits (Fig. 5). In the Blue Rhino kit, the tracheostomy tube is loaded onto an appropriately sized dilator, whereas the ULTRAperc kit provides a separate special tapered introducer for the tracheostomy tube insertion step.

A comparison of the 2 sets was performed using both mannequin and porcine airway models. During dilation, the Blue Rhino caused less mean percentage anterior-posterior compression $(34.8 \%$ vs $51.5 \%, P=.001)$. In contrast, during insertion of the tracheostomy tube, the ULTRAperc was subjectively easier in the porcine airway model and had a shorter median insertion time in both mannequin and porcine models, and the mean percentage anterior-posterior compression was less in the mannequin model $(51.5 \%$ vs $76 \%, P=.001)$. There was no difference in the incidence of posterior wall damage between the 2 sets. The ULTRAperc has some advantages during tracheostomy tube insertion that are probably due to the presence of the tracheostomy tube introducer. ${ }^{77}$

\section{Challenges With Percutaneous Dilatational Tracheostomy and New Solutions}

Diametrical Differences Between Loading Dilators and Percutaneous Tracheostomy Tubes. At the distal end of the tracheostomy tube, there can be a gap between the loading dilator and the tube that can make insertion of the tracheostomy tube challenging (Fig. 6). This can cause a deformity of the tracheostomy tube during the process of attempted insertion. Best-fit combinations of tracheostomy tube and loading dilators have been established: size 8 Shiley tracheostomy with the 28 French loading dilator and size 8 Bivona Hyperflex and Portex Blue Line adjustable flange with the 24 French loading dilator. There is no 


\section{TRACHEOSTOMY}

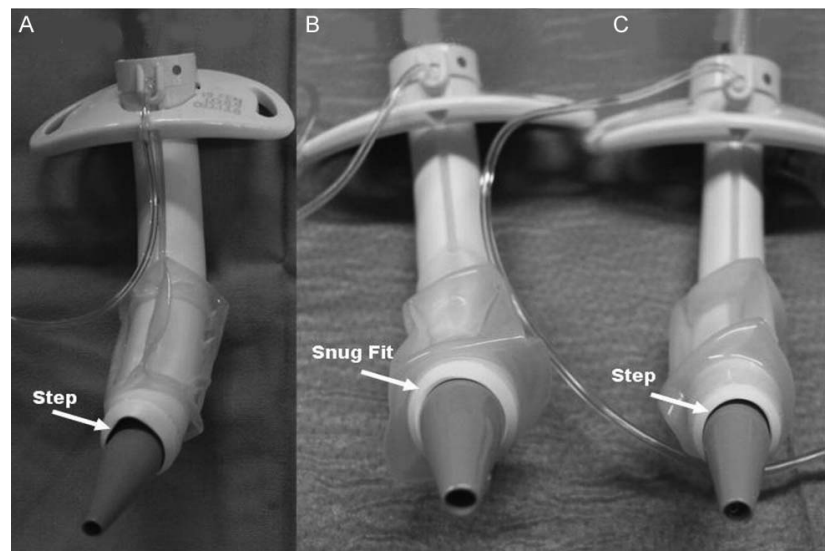

Fig. 6. Diametrical differences between percutaneous dilatational tracheostomy loading dilators and percutaneous tracheostomy tubes. A: Size 10 Shiley over a 28 French (28F) loading dilator leaves an escalated step. Note the deformity (arrow) caused by the step during the insertion of the tube. A good fit combination is shown in B: Size 8 Shiley and a 28 French loading dilator, showing no gap between the loading dilator and the tube (arrow). C: Example of another sizing issue, size 6 Shiley loaded over a 24 French (24F) dilator, again showing the step deformity (arrow). From Reference 78, with permission. Images courtesy Dr Amer Majeed.

gap between the loading dilator and tracheostomy tube when these combinations are used.

New Longer Tapered Tip and Low-Profile Tracheostomy Tubes for PDT. A simple solution to the poor fit of regular tracheostomy tubes and loading dilators in the PDT kit is to use tracheostomy tubes that are made specifically for PDT with a longer distal tapered tip and a low-profile cuff (Fig. 7). This reduces the force required for tracheostomy insertion with PDT and allows a safer and more rapid procedure to be performed.
Need for Proximal or Distal Extension Tracheostomy. Proximal extension tracheostomy may be required with thick neck anatomy and in obese patients, and distal extension tracheostomy may be required in patients with long tracheal anatomy, tracheal obstruction (to get the tip distal to the obstruction), or tracheomalacia (Fig. 8). PDT has been contraindicated in these patients, but the recent development and availability of new longer percutaneous tracheostomy tubes (VersaTube, Cook Medical) have provided additional PDT options for those challenging patients who require distal extension tracheostomy.

\section{Two New Percutaneous Tracheostomy Procedures}

Ciaglia Blue Dolphin. The new balloon dilation PDT technique primarily uses radial force to widen the tracheostomy (Ciaglia Blue Dolphin system) (Fig. 9). The initial experience with this method reported that tracheostomy surgery time averaged $3.3 \pm 1.9$ min with minimal complications. ${ }^{79}$ Another single-center study randomized trial $(n=70)$ comparing single-step (Rhino) and balloon (Dolphin) dilatational tracheostomy in ICU subjects reported that median procedure time was significantly shorter in the Rhino group compared with the Dolphin group (1.5 vs $4 \mathrm{~min}, P=.035$ ), and the presence of limited intratracheal bleeding at bronchoscopy $6 \mathrm{~h}$ post-procedure was more frequent in the Dolphin group (68.6\% vs $34.3 \%, P=.008$ ). Although the Blue Dolphin technique was feasible, the PDT Rhino technique had a shorter execution time and was associated with fewer tracheal injuries. Additional studies are warranted to validate these disparate findings.

PercuTwist. The controlled rotating dilatation method (PercuTwist) is a relatively new technique and was used in an early versus late tracheotomy study in an Italian

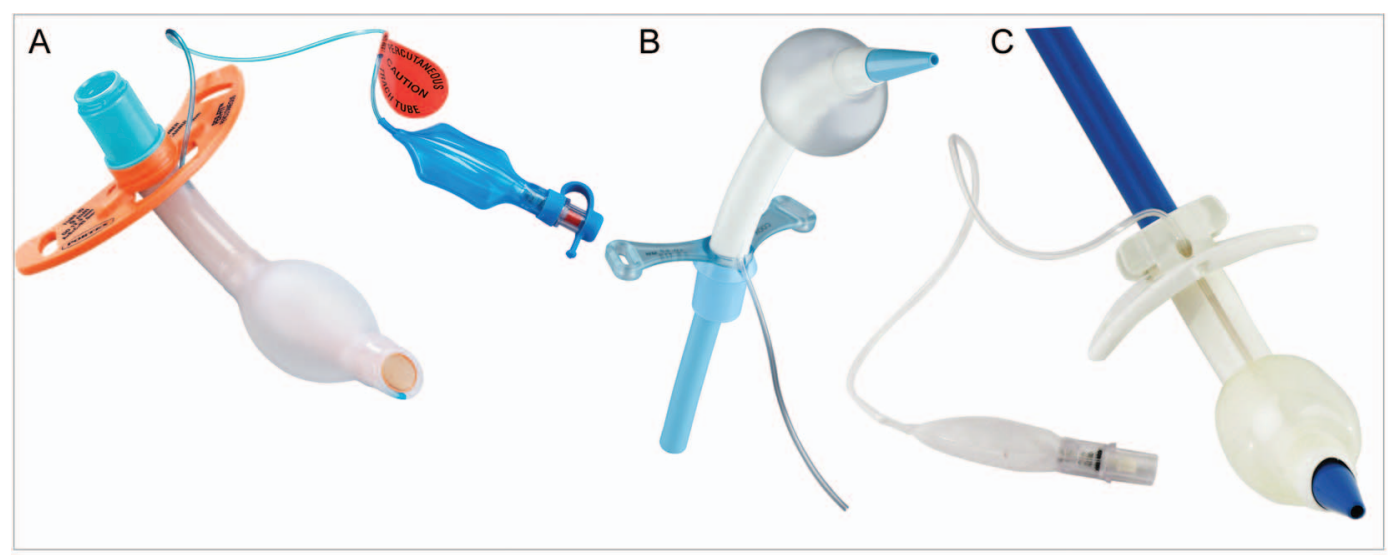

Fig. 7. Tapered tracheostomy tubes for use with percutaneous dilatational tracheostomy to avoid poor fit with tapered dilators. A: Portex Per-Fit (courtesy Smiths Medical). B: VersaTube (courtesy Cook Medical). C: Shiley PERC (courtesy Covidien). 


\section{TRACHEOSTOMY}

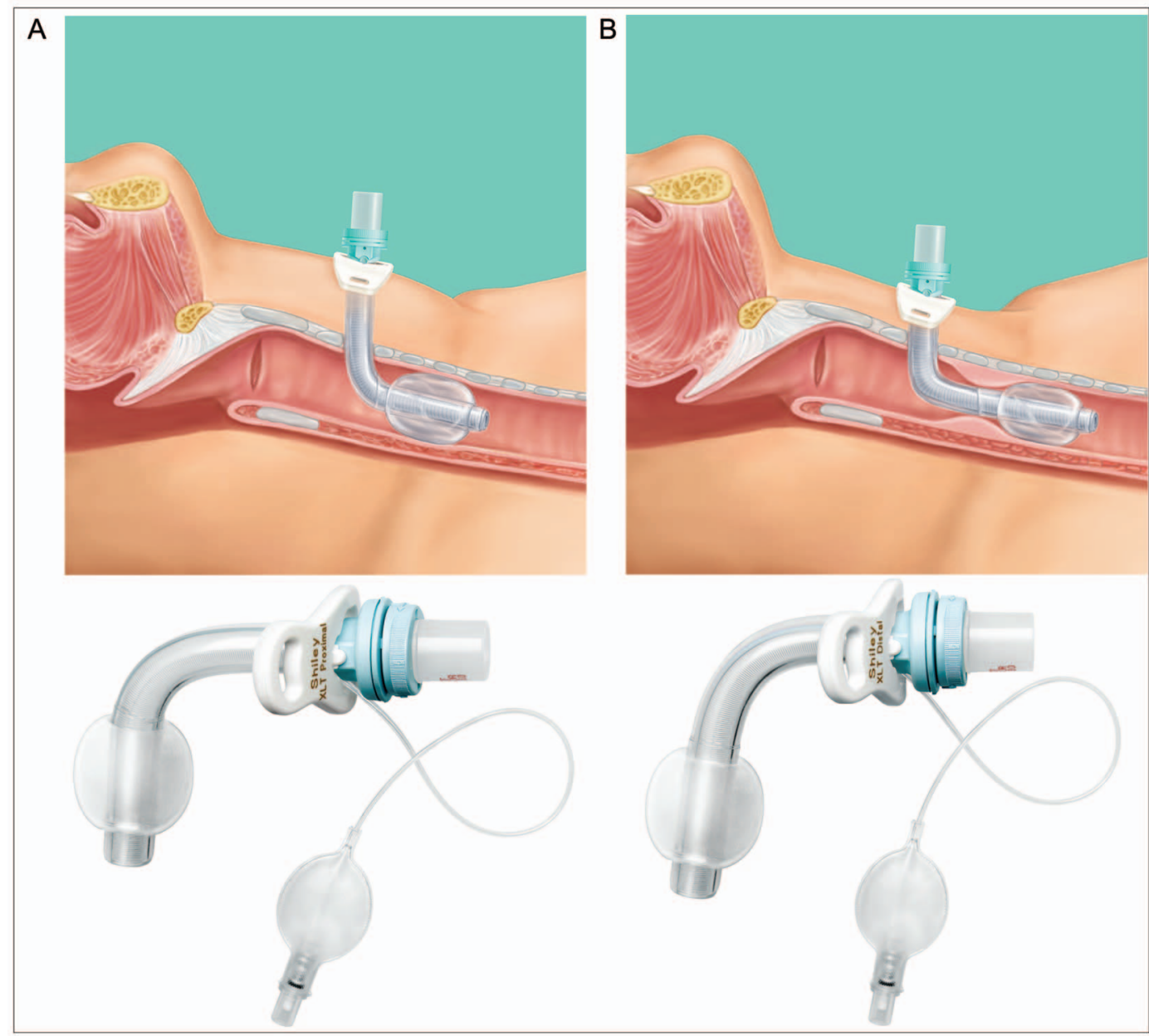

Fig. 8. Percutaneous dilatational tracheostomy limitations: need for proximal or distal extension tracheostomy. A: Proximal extension for full or thick neck. B: Distal extension for long tracheal anatomy, tracheal stenosis, or tracheomalacia. Courtesy Covidien.

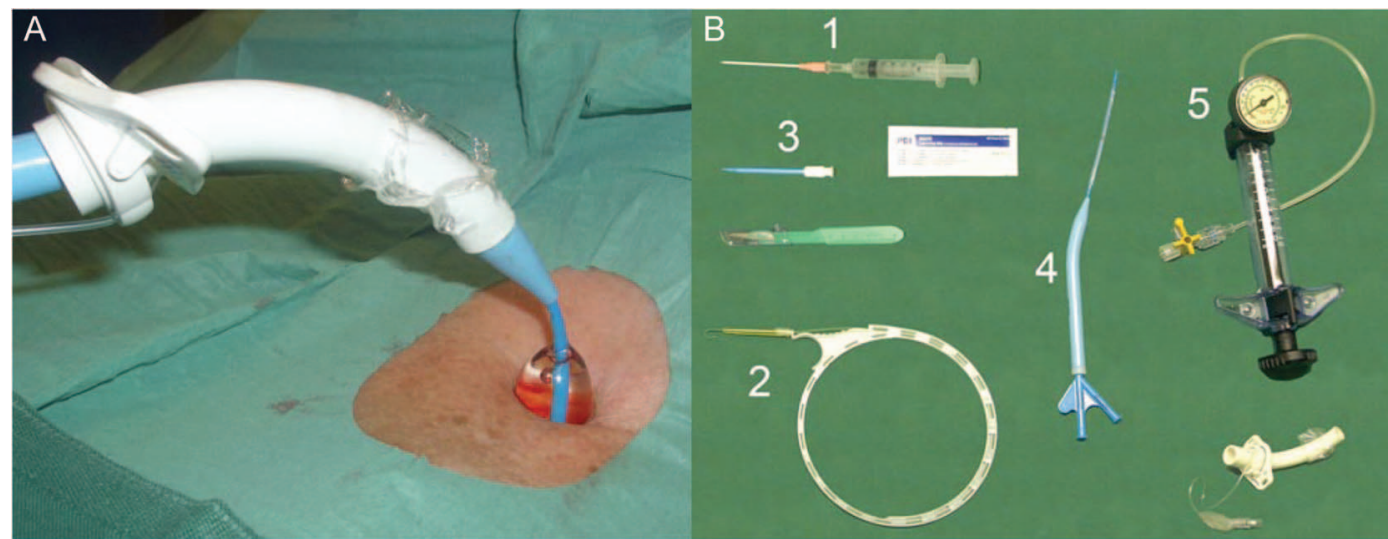

Fig. 9. Ciaglia Blue Dolphin percutaneous technique. This is a safe and effective percutaneous tracheostomy technique that uses radial outward dilation to minimize bleeding and injury to tracheal rings. Tracheostomy surgery time averaged $3.3 \pm 1.9$ min, with no evidence of increased complications. A: Balloon inflation with normal saline to a maximum pressure of 11 atm using an inflation pump. The balloon protrudes 1-1.5 cm above the skin surface. B: Ciaglia Blue Dolphin components: (1) introducer needle, (2) guide wire, (3) 14 French dilator, (4) balloon-tipped catheter loading dilator assembly, (5) Cook inflation device. From Reference 79, with permission. 


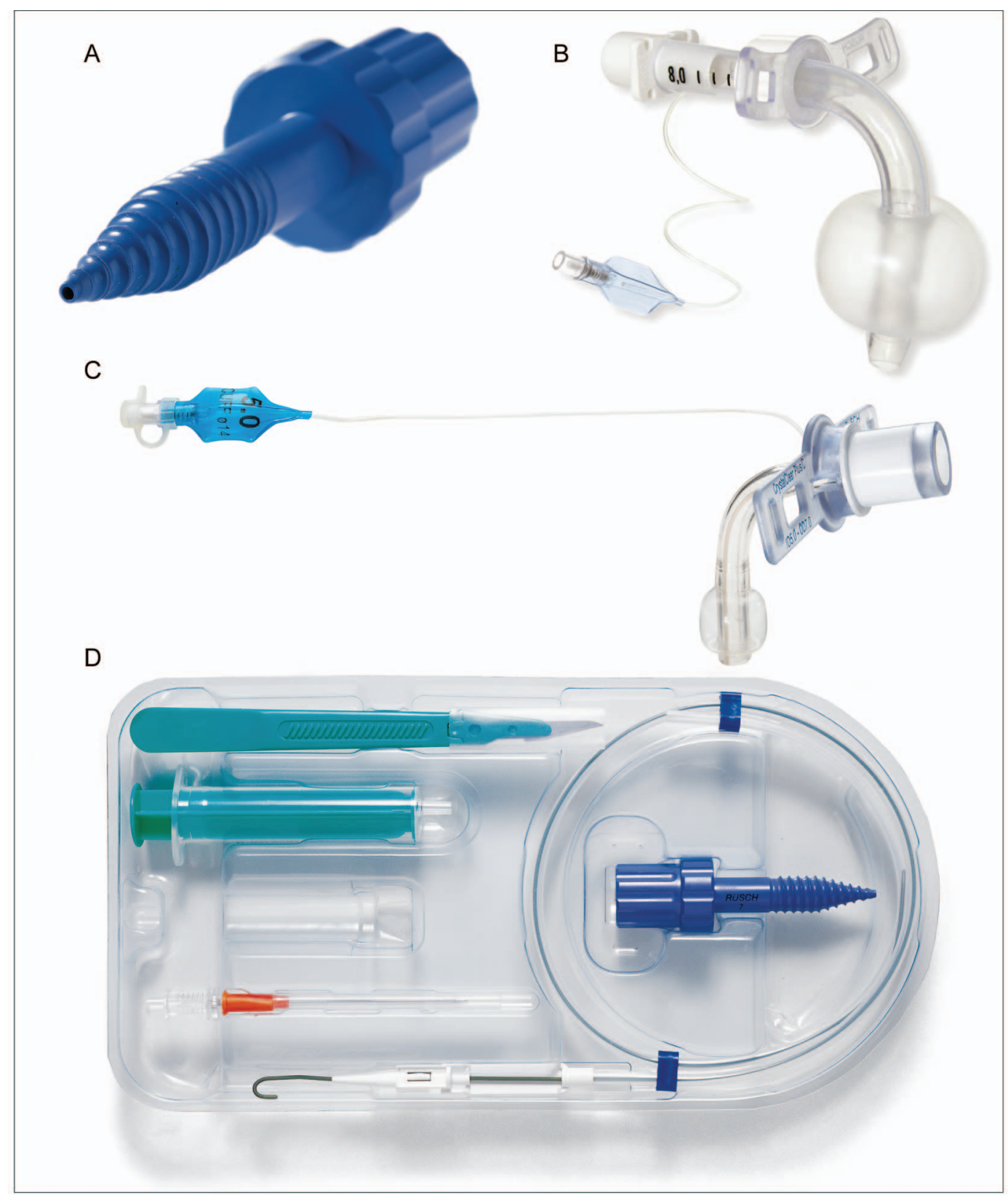

Fig. 10. PercuTwist technique for percutaneous tracheostomy. A: PercuTwist dilator. B: CrystalClear cannula. C: PercuQuick cannula. D: PercuTwist set. Courtesy Teleflex.

multi-center trial (Fig. 10). ${ }^{53}$ A recent study compared percutaneous tracheostomy techniques $(n=130)$ of PDT, the guide wire dilating forceps technique (Griggs) and the PercuTwist technique. The duration of the procedure was significantly shorter in the PercuTwist group compared with both other groups. ${ }^{80}$ It was easy to perform, was associated with minimal complications, and is a practical alternative to the PDT technique, which is most commonly performed. Limitations of this study include the small sample size, the use of the Ciaglia multiple-dilator kit for PDT (which is inferior to the single-dilator kit), and comparison to a technique that is not used frequently (the guide wire dilating forceps technique).

\section{High-Risk Patients and Percutaneous Dilatational Tracheostomy}

There have been a handful of retrospective small studies examining complication rates for percutaneous tracheostomy in high-risk patients with coagulopathy, thrombocy- 


\section{TRACHEOSTOMY}

topenia, and other bleeding diatheses, with or without correction at the discretion of the physician performing the tracheostomy. These studies have documented few bleeding complications. ${ }^{81-83}$ While all of these studies are relatively small, they suggest that judicious correction of coagulopathy in the periprocedural period allows for safe PDT in the coagulopathic patient.

Obesity is another factor that drives practitioners to choose surgical tracheostomy over PDT due to concern about complication risks. A number of small retrospective studies documented no difference in complication rates with the PDT procedure in obese patients. ${ }^{84-88}$

The largest study examining this issue reported a singlecenter prospective analysis of 1,000 PDT procedures (20012009) in ICU subjects with increased bleeding risk or obesity. ${ }^{89}$ They identified that increased international normalized ratio was the most important risk factor for bleeding (OR 2.99, 95\% CI 1.26-7.08), followed by thrombocytopenia with platelet count $<100,000$ cells/ $\mu \mathrm{L}$ (OR $1.99,95 \%$ CI $0.99-3.95)$. Interestingly, platelet dysfunction associated with continuous renal replacement therapy was not associated with increased bleeding risk (OR 1.02, 95\% CI 0.39-2.66). The rate of complications in subjects with high body mass index was not increased.

The decision to perform percutaneous tracheostomy in a patient with obesity or coagulopathy should take into account factors such as the individual patient's neck anatomy and experience of the performing physician, and the practitioner must be prepared to convert to the open surgical technique if complications are encountered during the PDT procedure.

\section{Procedural Cost of Tracheostomy}

A number of studies have reviewed the potential significant cost savings related to PDT versus surgical open tracheostomy (Fig. 4). ${ }^{90-92}$ On average, procedural costs for PDT are $\sim 50 \%$ less than those for open surgical tracheostomy, and the reduced cost is mostly related to lack of use of the operating room and anesthesia teams. The cost difference does depend, however, on whether the open surgical tracheostomy is performed in the operating room or bedside in the ICU. We have the capability to perform open tracheostomy at the ICU bedside and have all appropriate equipment, including headlights, operating room portable light, fine-point electrocautery, and surgical tracheostomy trays.

\section{Tracheostomy Decannulation}

Decisions regarding optimal timing for tracheostomy decannulation require clinical judgment, particularly with determination that the indication for tracheostomy tube placement has resolved. ${ }^{93} \mathrm{~A}$ recent clinical consensus state-
Table 8. Prerequisites for Tracheostomy Decannulation in Adult Patients

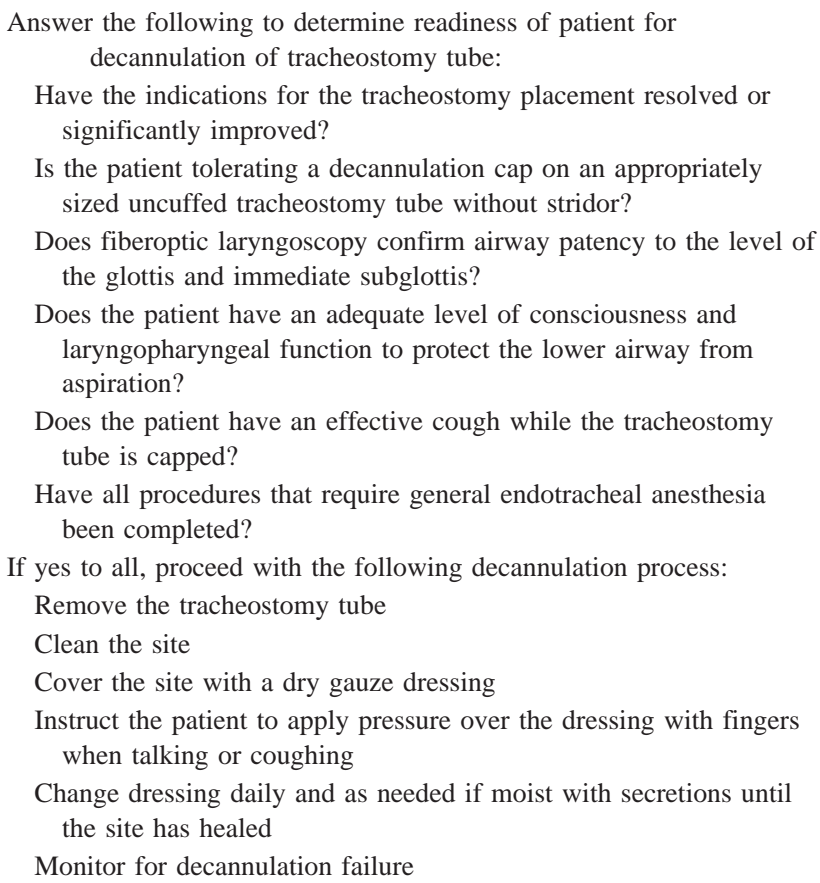

Have the indications for the tracheostomy placement resolved or significantly improved?

Is the patient tolerating a decannulation cap on an appropriately sized uncuffed tracheostomy tube without stridor?

Does fiberoptic laryngoscopy confirm airway patency to the level of the glottis and immediate subglottis?

Does the patient have an adequate level of consciousness and laryngopharyngeal function to protect the lower airway from aspiration?

Does the patient have an effective cough while the tracheostomy tube is capped?

Have all procedures that require general endotracheal anesthesia been completed?

If yes to all, proceed with the following decannulation process:

Remove the tracheostomy tube

Clean the site

Cover the site with a dry gauze dressing

Instruct the patient to apply pressure over the dressing with fingers when talking or coughing

Change dressing daily and as needed if moist with secretions until the site has healed

Monitor for decannulation failure

In addition to the factors listed above, consider the type and amount of tracheal secretions and the frequency of tracheal suctioning required prior to consideration of decannulation. Adapted from Reference 94.

ment on tracheostomy care used a Delphi approach and achieved consensus on 77 statements with the goal to reduce variations in practice when managing patients with a tracheostomy to minimize complications. ${ }^{94} \mathrm{~A}$ list of prerequisites for consideration for tracheostomy decannulation in adults is provided (Table 8), and we strongly recommend additional consideration of the type and quantity of secretions and frequency of suctioning required.

\section{Additional Recent Advances in Tracheostomy}

\section{Real-Time Ultrasound}

A recent systematic review examined published data regarding the safety and efficacy of ultrasound before and/or during PDT. ${ }^{95}$ There are currently no randomized trials to establish the safety or efficacy of preprocedural and/or real-time ultrasound guidance during PDT compared with the current standard of care. Studies to date include (1) ultrasound before PDT (no controlled trials; 2 observational studies suggested a possible benefit in avoiding serious complications by identifying vulnerable vascular structures) and (2) real-time ultrasound during PDT (one controlled study that retrospectively compared real-time 


\section{TRACHEOSTOMY}

ultrasound guidance with the landmark-guided technique and found it to be superior in avoiding cranial misplacement; it appeared to be safe and effective in 2 observational studies). This review concluded that a prospective randomized trial evaluating ultrasound safety and efficacy compared with the traditional landmark-guided technique is required to establish its role in clinical practice.

In a single-institution prospective observational study, 13 subjects successfully underwent real-time ultrasoundguided PDT. Three patients were morbidly obese, 2 were in cervical spine precautions, and one had a previous tracheostomy. In all 13 subjects bronchoscopy confirmed that guide wire entry was through the anterior wall and between the first and fifth tracheal rings. There was no case of tube misplacement, pneumothorax, posterior wall injury, significant bleeding, or other complications. ${ }^{96} \mathrm{Al}-$ though ultrasound may not be required in all patients undergoing PDT, real-time ultrasound should be considered in obese patients in whom surface landmarks are difficult to discern, in patients with altered cervical anatomy, and for difficult tracheostomy procedures such as repeat tracheostomy. ${ }^{97}$

Another prospective study of 50 consecutive subjects in 2 surgical and critical care medicine departments in France demonstrated that ultrasound-guided percutaneous tracheostomy was feasible and safe in obese patients (median body mass index of $34 \mathrm{~kg} / \mathrm{m}^{2}$, range of 32-38) with a low complication rate. This study demonstrated that ultrasound examination provided information on cervical anatomy that modified and guided the specific choice for the puncture site for the percutaneous tracheostomy procedure. ${ }^{98}$

There are some potential advantages to the real-time ultrasound PDT technique, including (1) decreased hypercarbia and associated increased intracranial pressure in neurologic and TBI patients due to no bronchoscope in the airway; (2) avoidance of vascular structures in the anterior neck, particularly the midline thyroid veins; and (3) direct visualization of the site of entry into the trachea and determination of which tracheal ring, which is particularly useful in patients with difficult surface anatomy, morbid obesity, and previous tracheostomy. Until additional studies are available, point-of-care ultrasound is used with increasing frequency to augment diagnosis and therapy for critically ill patients, and this is another indication for ultrasound use in challenging patients requiring PDT.

\section{Multidisciplinary Tracheostomy Team}

A previous study documented that the use of an intensivist-led tracheostomy team is associated with shorter decannulation time and stay. ${ }^{99}$ Additional studies have reported that the use of a dedicated multidisciplinary team designed to streamline tracheostomy practice was associ- ated with increased PDT, decreased procedural complications, reduced procedure time, and improved efficiency. In a study from The Johns Hopkins University School of Medicine, the implementation of a multidisciplinary percutaneous tracheostomy team documented a significant reduction in airway injury $(6.8 \%$ vs $1.1 \%, P=.006)$, hypoxemia (13.6\% vs $3.3 \%, P=.005)$, loss of airway $(5.1 \%$ vs $0.5 \%, P=.039)$, and overall complication rate $(25.4 \%$ vs $4.9 \%, P<.001$ ) (http://www.hopkinsmedicine.org/ tracheostomy. Accessed June 14, 2013). ${ }^{100}$ No difference in stomal infection or mortality was identified. Other institutions have established similar tracheostomy teams to provide optimal care for these challenging patients (http:// www.tracheostomyteam.org. Accessed June 14, 2013). Tracheostomy teams enhance consistency of patient care and implementation of standardized protocols of care.

\section{National Tracheostomy Safety Project}

The UK National Tracheostomy Safety Project has standardized resources for education of both health care providers and patients (http://tracheostomy.org.uk. Accessed June 14, 2013). Three self-directed learning modules include (1) basic knowledge (anatomy, physiology, indications, procedures); (2) emergency management (tracheostomy and laryngectomy), and (3) nursing and general care, including associated devices. Emergency algorithms were developed by consensus, and the final algorithms describe a universal approach to management of tracheostomy emergencies (Fig. 11). This project aims to improve the management of tracheostomy critical incidents. ${ }^{101}$

\section{Conclusions}

In conclusion, there is no benefit to early tracheostomy in most ICU patients with acute respiratory failure, and waiting until $\geq 10 \mathrm{~d}$ of intubation and mechanical ventilation is recommended to determine whether ongoing respiratory support is required. Special patient populations may benefit from early tracheostomy, including (1) high likelihood of prolonged mechanical ventilation (ARDS, COPD, failed primary extubation), (2) SCI and chronic neurologic disorders, and (3) TBI patients and other patients with need for airways.

Recent large randomized trials have confirmed that clinicians and intensivists are poor in predicting who will need prolonged intubation and mechanical ventilation. There is a need for tools to accurately predict which patients will require prolonged intubation and therefore could benefit from earlier tracheostomy. These tools are not yet available.

The optimal technique for tracheostomy is PDT with bronchoscopic guidance, except in those patients with contraindications to PDT (coagulopathy, thrombocyto- 


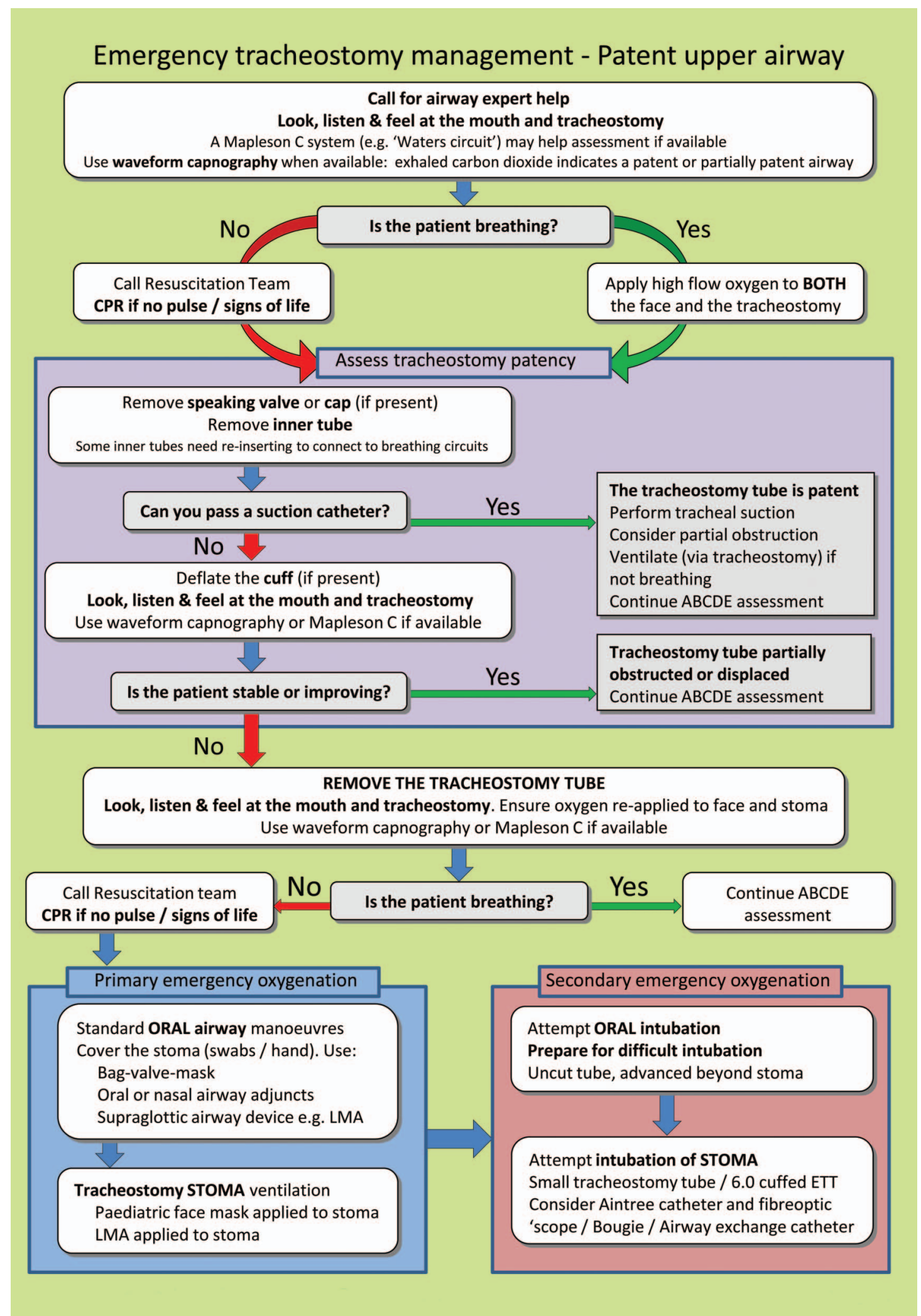

Fig. 11. UK National Tracheostomy Safety Project algorithm. CPR $=$ cardiopulmonary resuscitation. ABCDE $=$ airway, breathing, circulation, disability, exposure. LMA = laryngeal mask airway. ETT = endotracheal tube. From Reference 101, with permission. 


\section{TRACHEOSTOMY}

penia, other risk factors for bleeding, inadequate surface landmarks, inability to tolerate hypoxemia or hypercarbia, need for proximal or distal extension tracheostomy). Choice of technique must take into account both individual and institutional experience, body habitus, risk factors for bleeding, and pathophysiology (ie, presence or absence of airway obstruction, difficulty of endotracheal intubation).

A number of new advances in tracheostomy are under way. The use of real-time ultrasound guidance for PDT tracheostomy has been shown to be useful in patients without surface landmarks, in obese and repeat tracheostomy patients, and in patients with altered cervical anatomy. New tracheostomy tubes and techniques include longer percutaneous tracheostomy tubes and low-profile tubes that fit better on the dilators for PDT and a percutaneous balloon inflation technique.

Finally, it has been demonstrated that tracheostomy teams and a tracheostomy hospital service were associated with standardized protocols and improved outcomes. The UK National Tracheostomy Safety Project has standardized resources for education for both health care providers and patients, including emergency algorithms for tracheostomy incidents.

\section{REFERENCES}

1. Ranes JL, Gordon SM, Chen P, Fatica C, Hammel J, Gonzales JP, Arroliga AC. Predictors of long-term mortality in patients with ventilator-associated pneumonia. Am J Med 2006;119(10):897.e13899.e13.

2. Holzapfel L, Chevret S, Madinier G, Ohen F, Demingeon G, Coupry A, Chaudet M. Influence of long-term oro- or nasotracheal intubation on nosocomial maxillary sinusitis and pneumonia: results of a prospective, randomized, clinical trial. Crit Care Med 1993;21(8):1132-1138.

3. Cavaliere S, Bezzi M, Toninelli C, Foccoli P. Management of postintubation tracheal stenoses using the endoscopic approach. Monaldi Arch Chest Dis 2007;67(2):73-80.

4. Heffner JE, Hess D. Tracheostomy management in the chronically ventilated patient. Clin Chest Med 2001;22(1):55-69.

5. Nieszkowska A, Combes A, Luyt CE, Ksibi H, Trouillet JL, Gibert C, Chastre J. Impact of tracheotomy on sedative administration, sedation level, and comfort of mechanically ventilated intensive care unit patients. Crit Care Med 2005;33(11):2527-2533.

6. Diehl JL, El Atrous S, Touchard D, Lemaire F, Brochard L. Changes in the work of breathing induced by tracheotomy in ventilatordependent patients. Am J Respir Crit Care Med 1999;159(2):383388.

7. François B, Clavel M, Desachy A, Puyraud S, Roustan J, Vignon P. Complications of tracheostomy performed in the ICU: subthyroid tracheostomy vs surgical cricothyroidotomy. Chest 2003;123(1): 151-158.

8. Pierson DJ. Tracheostomy from A to Z: historical context and current challenges. Respir Care 2005;50(4):473-475.

9. McClelland RM. Tracheostomy: its management and alternatives. Proc R Soc Med 1972;65(4):401-404.

10. Golzari SE, Khan ZH, Ghabili K, Hosseinzadeh H, Soleimanpour $\mathrm{H}$, Azarfarin R, et al. Contributions of Medieval Islamic physicians to the history of tracheostomy. Anesth Analg 2013;116(5):11231132.

11. Goodall EW. On infectious diseases and epidemiology in the Hippocratic collection: (Section of the History of Medicine). Proc R Soc Med 1934;27(5):525-534.

12. Jackson C. Tracheotomy. Laryngoscope 1909;19:285-290.

13. Lassen HC. A preliminary report on the 1952 epidemic of poliomyelitis in Copenhagen with special reference to the treatment of acute respiratory insufficiency. Lancet 1953;1(6749):37-41.

14. Wunsch H, Linde-Zwirble WT, Angus DC, Hartman ME, Milbrandt EB, Kahn JM. The epidemiology of mechanical ventilation use in the United States. Crit Care Med 2010;38(10):1947-1953.

15. Needham DM, Bronskill SE, Sibbald WJ, Pronovost PJ, Laupacis A. Mechanical ventilation in Ontario, 1992-2000: incidence, survival, and hospital bed utilization of noncardiac surgery adult patients. Crit Care Med 2004;32(7):1504-1509.

16. Needham DM, Bronskill SE, Calinawan JR, Sibbald WJ, Pronovost PJ, Laupacis A. Projected incidence of mechanical ventilation in Ontario to 2026: preparing for the aging baby boomers. Crit Care Med 2005;33(3):574-579.

17. Carson SS, Cox CE, Holmes GM, Howard A, Carey TS. The changing epidemiology of mechanical ventilation: a population-based study. J Intensive Care Med 2006;21(3):173-182.

18. Quality of Life After Mechanized Ventilation in the Elderly Study Investigators. Two-month mortality and functional status of critically ill adult patients receiving prolonged mechanical ventilation. Chest 2002;121(2):549-558.

19. Owings MF, Kozak LJ. Ambulatory and inpatient procedures in the United States, 1996. National Center for Health Statistics, Vital Health Statistics, 1998. www.cdc.gov/nchs/data/series/sr_13/ sr13_139.pdf. Accessed June 14, 2013.

20. Yu M. Tracheostomy patients on the ward: multiple benefits from a multidisciplinary team? Crit Care 2010;14(1):109.

21. Cox CE, Carson SS, Holmes GM, Howard A, Carey TS. Increase in tracheostomy for prolonged mechanical ventilation in North Carolina, 1993-2002. Crit Care Med 2004;32(11):2219-2226.

22. De Leyn P, Bedert L, Delcroix M, Depuydt P, Lauwers G, Sokolov Y, et al. Tracheotomy: clinical review and guidelines. Eur J Cardiothorac Surg 2007;32(3):412-421.

23. Rana S, Pendem S, Pogodzinski MS, Hubmayr RD, Gajic O. Tracheostomy in critically ill patients. Mayo Clin Proc 2005;80(12): 1632-1638.

24. Freeman BD, Borecki IB, Coopersmith CM, Buchman TG. Relationship between tracheostomy timing and duration of mechanical ventilation in critically ill patients. Crit Care Med 2005;33(11): 2513-2520.

25. Frutos-Vivar F, Esteban A, Apezteguía C, Anzueto A, Nightingale $\mathrm{P}$, González M, et al. Outcome of mechanically ventilated patients who require a tracheostomy. Crit Care Med 2005;33(2):290-298.

26. Nathens AB, Rivara FP, Mack CD, Rubenfeld GD, Wang J, Jurkovich GJ, Maier RV. Variations in rates of tracheostomy in the critically ill trauma patient. Crit Care Med 2006;34(12):2919-2924.

27. Durbin CG Jr. Early complications of tracheostomy. Respir Care 2005;50(4):511-515.

28. Epstein SK. Late complications of tracheostomy. Respir Care 2005; 50(4):542-549.

29. Freeman BD, Stwalley D, Lambert D, Edler J, Morris PE, Medve$\operatorname{dev} \mathrm{S}$, et al. High resource utilization does not affect mortality in acute respiratory failure patients managed with tracheostomy. Respir Care 2013;58(11):1863-1872.

30. Engoren M, Arslanian-Engoren C, Fenn-Buderer N. Hospital and long-term outcome after tracheostomy for respiratory failure. Chest 2004;125(1):220-227. 


\section{TRACHEOSTOMY}

31. Combes A, Luyt CE, Nieszkowska A, Trouillet JL, Gibert C, Chastre J. Is tracheostomy associated with better outcomes for patients requiring long-term mechanical ventilation? Crit Care Med 2007; 35(3):802-807

32. Clec'h C, Alberti C, Vincent F, Garrouste-Orgeas M, de Lassence A, Toledano D, et al. Tracheostomy does not improve the outcome of patients requiring prolonged mechanical ventilation: a propensity analysis. Crit Care Med. 2007; 35(1):132-138.

33. Rumbak MJ, Newton M, Truncale T, Schwartz SW, Adams JW, Hazard PB. A prospective, randomized, study comparing early percutaneous dilatational tracheostomy to prolonged translaryngeal intubation (delayed tracheostomy) in critically ill medical patients. Crit Care Med 2004;32(8):1689-1694.

34. Scales DC, Thiruchelvam D, Kiss A, Redelmeier DA. The effect of tracheostomy timing during critical illness on long-term survival. Crit Care Med 2008;36(9):2547-2557.

35. Terragni PP, Antonelli M, Fumagalli R, Faggiano C, Berardino M, Pallavicini FB, et al. Early vs late tracheotomy for prevention of pneumonia in mechanically ventilated adult ICU patients: a randomized controlled trial. JAMA 2010;303(15):1483-1489.

36. Young D, Harrison DA, Cuthbertson BH, Rowan K, TracMan Collaborators. Effect of early vs late tracheostomy placement on survival in patients receiving mechanical ventilation: the TracMan randomized trial. JAMA 2013;309(20):2121-2129.

37. Bittner EA, Schmidt UH. The ventilator liberation process: Update on technique, timing and termination of tracheostomy. Respir Care 2012;57(10):1626-1634.

38. Durbin CG. Tracheostomy: why, when and how? Respir Care 2010; 55(8):1056-1068.

39. Plummer AL, Gracey DR. Consensus conference on artificial airways in patients receiving mechanical ventilation. Chest 1989;96(1): 178-1780.

40. Freeman BD, Morris PE. Tracheostomy practice in adults with acute respiratory failure. Crit Care Med 2012;40(10):2890-2896.

41. Arabi YM, Alhashemi JA, Tamim HM, Esteban A, Haddad SH, Dawood A, et al. The impact of time to tracheostomy on mechanical ventilation duration, length of stay, and mortality in intensive care unit patients. J Crit Care 2009;24(3):435-440.

42. Beltrame F, Zussino M, Martinez B, Dibartolomeo S, Saltarini M, Vetrugno L, et al. Percutaneous versus surgical bedside tracheostomy in the intensive care unit: a cohort study. Minerva Anestesiol 2008;74(10):529-535.

43. Möller MG, Slaikeu JD, Bonelli P, Davis AT, Hoogeboom JE, Bonnell BW. Early tracheostomy versus late tracheostomy in the surgical intensive care unit. Am J Surg 2005;189(3):293-296.

44. Olton S, Hariharan S, Chen D. Outcome evaluation of patients requiring tracheostomy in an intensive care unit in Trinidad. West Indian Med J 2009;58(2):173-178.

45. Zheng Y, Sui F, Chen XK, Zhang GC, Wang XW, Zhao S, et al. Early versus late percutaneous dilational tracheostomy in critically ill patients anticipated requiring prolonged mechanical ventilation. Chin Med J 2012;125(11):1925-1930.

46. Hsu CL, Chen KY, Chang CH, Jerng JS, Yu CJ, Yang PC. Timing of tracheostomy as a determinant of weaning success in critically ill patients: a retrospective study. Crit Care 2005;9(1):R46-R52.

47. Rodriguez JL, Steinberg SM, Luchetti FA, Gibbons KJ, Taheri PA, Flint LM. Early tracheostomy for primary airway management in the surgical critical care setting. Surgery 1990;108(4):655-659.

48. Saffle JR, Morris SE, Edelman L. Early tracheostomy does not improve outcome in burn patients. J Burn Care Rehabil 2002;23(6): 431-438

49. Bouderka MA, Fakhir B, Bouaggad A, Hmamouchi B, Hamoudi D, Harti A. Early tracheostomy versus prolonged endotracheal intubation in severe head injury. J Trauma 2004;57(2):251-254.
50. Griffiths J, Barber VS, Morgan L, Young JD. Systematic review and meta-analysis of studies of the timing of tracheostomy in adult patients undergoing artificial ventilation. BMJ 2005;330(7502): 1243.

51. Fartoukh M, Maitre B, Honoré S, Cerf C, Zahar JR, Brun-Buisson C. Diagnosing pneumonia during mechanical ventilation: the clinical pulmonary infection score revisited. Am J Respir Crit Care Med 2003;168(2):173-179.

52. Griggs WM, Myburgh JA, Worthley LI. A prospective comparison of a percutaneous tracheostomy technique with standard surgical tracheostomy. Intensive Care Med 1991;17(5):261-263.

53. Frova G, Quintel M. A new simple method for percutaneous tracheostomy: controlled rotating dilation: a preliminary report. Intensive Care Med 2002;28(3):299-303.

54. Napolitano LM. Use of severity scoring and stratification factors in clinical trials of hospital-acquired and ventilator-associated pneumonia. Clin Infect Dis 2010;51(Suppl 1):S67-S80.

55. Lauzier F, Ruest A, Cook D, Dodek P, Albert M, Shorr AF, et al. The value of pretest probability and modified clinical pulmonary infection score to diagnose ventilator-associated pneumonia. J Crit Care 2008;23(1):50-57.

56. Barquist ES, Amortegui J, Hallal A, Giannotti G, Whinney R, Alzamel H, MacLeod J. Tracheostomy in ventilator dependent trauma patients: a prospective, randomized intention-to-treat study. J Trauma 2006;60(1):91-97.

57. Blot F, Similowski T, Trouillet JL, Chardon P, Korach JM, Costa MA, et al. Early tracheotomy versus prolonged endotracheal intubation in unselected severely ill ICU patients. Intensive Care Med 2008;34(10):1779-1787.

58. Trouillet JL, Luyt CE, Guiguet M, Ouattara A, Vaissier E, Makri R, et al. Early percutaneous tracheotomy versus prolonged intubation of mechanically ventilated patients after cardiac surgery: a randomized trial. Ann Intern Med 2011;154(6):373-383.

59. Wang F, Wu Y, Bo L, Lou J, Zhu J, Chen F, et al. The timing of tracheotomy in critically ill patients undergoing mechanical ventilation: a systematic review and meta-analysis of randomized controlled trials. Chest 2011;140(6):1456-1465.

60. Dunham CM, LaMonica C. Prolonged tracheal intubation in the trauma patient. J Trauma 1984;24(2):120-124.

61. Gomes Silva BN, Andriolo RB, Saconato H, Atallah AN, Valente O. Early versus late tracheostomy for critically ill patients. Cochrane Database Syst Rev 2012;3:CD007271.

62. Centers for Medicare \& Medicaid Services. Acute Inpatient PPS: list of final MSDRGs, relative weighting factors and geometric and arithmetic mean length of stay. http://www.cms.gov/medicare/ medicare-fee-for-service-payment/acuteinpatientpps/fy-2013-ippsfinal-rule-home-page-items/fy2013-final-rule-tables.html. Accessed April 24, 2013.

63. Arabi Y, Haddad S, Shirawi N, Al Shimemeri A. Early tracheostomy in intensive care trauma patients improves resource utilization: a cohort study and literature review. Crit Care 2004;8(5): R347-R352.

64. Schauer JM, Engle LL, Maugher DT, Cherry RA. Does acuity matter? Optimal timing of tracheostomy stratified by injury severity. J Trauma 2009;66(1):220-225.

65. Ahmed N, Kuo YH. Early versus late tracheostomy in patients with severe traumatic head injury. Surg Infect 2007;8(3):343-347.

66. Pinheiro Bdo V, Tostes Rde O, Brum CI, Carvalho EV, Pinto SP, Oliveira JC. [Early versus late tracheostomy in patients with acute severe brain injury]. J Bras Pneumol 2010;36(1):84-91. Article in Portuguese.

67. Rizk EB, Patel AS, Stetter CM, Chinchilli VM, Cockroft KM. Impact of tracheostomy timing on outcome after severe head injury. Neurocrit Care 2011;15(3):481-489. 


\section{TRACHEOSTOMY}

68. Romero J, Vari A, Gambarrutta C, Oliviero A. Tracheostomy timing in traumatic spinal cord injury. Eur Spine J 2009;18(10):14521457.

69. Ganuza JR, Garcia Forcada A, Gambarrutta C, Diez De La Lastra Buigues E, Merlo Gonzalez VE, Paz Fuentes F, Luciani AA. Effect of technique and timing of tracheostomy in patients with acute traumatic spinal cord injury undergoing mechanical ventilation. J Spinal Cord Med 2011;34(1):76-84.

70. Jeon YT, Hwang JW, Lim YJ, Lee SY, Woo KI, Park HP. Effect of tracheostomy timing on clinical outcome in neurosurgical patients: early versus late tracheostomy. J Neurosurg Anesthesiol 2014;26(1): 22-26

71. Universitätsklinikum Hamburg-Eppendorf. Timing of dilation tracheostomy in mechanically ventilated chronic obstructive pulmonary disease (COPD) patients. http://www.clinicaltrials.gov. Accessed June 14, 2013.

72. Delaney A, Bagshaw SM, Nalos M. Percutaneous dilatational tracheostomy versus surgical tracheostomy in critically ill patients: a systematic review and meta-analysis. Crit Care 2006;10(2):R55.

73. Kong MS, Brietzke SE, Schindler JS, Bliznikas D, Baredes S, Close LG, et al. Percutaneous tracheotomy treatment and management. Medscape from WebMD. Updated July 2013. http://emedicine. medscape.com/article/866567-treatment\#a1133. Accessed March 13, 2014.

74. Durbin CG Jr. Techniques for performing tracheostomy. Respir Care 2005;50(4):488-496.

75. Higgins KM, Punthakee X. Meta-analysis comparison of open versus percutaneous tracheostomy. Laryngoscope 2007;117(3):447454.

76. Cabrini L, Monti G, Landoni G, Biondi-Zoccai G, Boroli F, Mamo $\mathrm{D}$, et al. Percutaneous tracheostomy, a systematic review. Acta Anaesthesiol Scand 2012;56(3):270-281.

77. Patel PB, Ferguson C, Patel A. A comparison of two single dilator percutaneous tracheostomy sets: the Blue Rhino and the ULTRAperc . Anaesthesia 2006;61(2):182-186.

78. Majeed A, Kannan S. Brief report: diametrical differences between Blue-Rhino kit loading dilators and percutaneous tracheostomy tubes. Anaesth Pain Intensive Care. http://www.apicareonline.com/ ?p=892. Accessed April 4, 2014.

79. Gromann TW, Birkelbach O, Hetzer R. [Ballon dilatational tracheostomy. Technique and first clinical experience with the Ciaglia Blue Dolphin method]. Chirurg 2009;80(7):622-627. Article in German.

80. Yurtseven N, Aydemir B, Karaca P, Aksoy T, Komurcu G, Kurt M, et al. PercuTwist: a new alternative to Griggs and Ciaglia's techniques. Eur J Anaesthesiol 2007;24(6):492-497.

81. Al Dawood A, Haddad S, Arabi Y, Dabbagh O, Cook DJ. The safety of percutaneous tracheostomy in patients with coagulopathy or thrombocytopenia. Middle East J Anesthesiol 2007;19(1): 37-49.

82. Auzinger G, O'Callaghan GP, Bernal W, Sizer E, Wendon JA. Percutaneous tracheostomy in patients with severe liver disease and a high incidence of refractory coagulopathy: a prospective trial. Crit Care 2007;11(5):R110.

83. Kluge S, Meyer A, Kühnelt P, Baumann HJ, Kreymann G. Percutaneous tracheostomy is safe in patients with severe thrombocytopenia. Chest 2004;126(2):547-551.
84. Byhahn C, Lischke V, Meininger D, Halbig S, Westphal K. Perioperative complications during percutaneous tracheostomy in obese patients. Anaesthesia 2005;60(1):12-15.

85. Aldawood AS, Arabi YM, Haddad S. Safety of percutaneous tracheostomy in obese critically ill patients: a prospective cohort study. Anaesth Intensive Care 2008;36(1):69-73.

86. Romero CM, Cornejo RA, Ruiz MH, Gálvez LR, Llanos OP, Tobar EA, et al. Fiberoptic bronchoscopy-assisted percutaneous tracheostomy is safe in obese critically ill patients: a prospective and comparative study. J Crit Care 2009;24(4):494-500.

87. Heyrosa MG, Melniczek DM, Rovito P, Nicholas GG. Percutaneous tracheostomy: a safe procedure in the morbidly obese. J Am Coll Surg 2006;202(4):618-622.

88. Blankenship DR, Kulbersh BD, Gourin CG, Blanchard AR, Terris DJ. High-risk tracheostomy: exploring the limits of the percutaneous tracheostomy. Laryngoscope 2005;115(6):987-989.

89. Rosseland LA, Laake JH, Stubhaug A. Percutaneous dilatational tracheotomy in intensive care unit patients with increased bleeding risk or obesity. A prospective analysis of 1000 procedures. Acta Anaesthesiol Scand 2011;55(7):835-841.

90. Bowen CP, Whitney LR, Truwit JD, Durbin CG, Moore MM. Comparison of safety and cost of percutaneous versus surgical tracheostomy. Am Surg 2001;67(1):54-60.

91. Cobean R, Beals M, Moss C, Bredenberg CE. Percutaneous dilatational tracheostomy. A safe, cost-effective bedside procedure. Arch Surg 1996;131(3):265-271.

92. Freeman BD, Isabella K, Cobb JP, Boyle WA 3rd, Schmieg RE Jr., Kolleff $\mathrm{MH}$, et al. A prospective, randomized study comparing percutaneous with surgical tracheostomy in critically ill patients. Crit Care Med 2001;29(5):926-930.

93. O'Connor HH, White AC. Tracheostomy decannulation. Respir Care 2010;55(8):1076-1081.

94. Mitchell RB, Hussey HM, Setzen G, Jacobs IN, Nussenbaum B, Dawson C, Brown CA 3rd, Brandt C, Deakins K, Hartnick C, Merati A. Clinical consensus statement: tracheostomy care. Otolaryngol Head Neck Surg 2013;148(1):6-20.

95. Rudas M, Seppelt I. Safety and efficacy of ultrasonography before and during percutaneous dilatational tracheostomy in adult patients: a systematic review. Crit Care Resusc 2012;14(4):297301.

96. Rajajee V, Fletcher JJ, Rochlen LR, Jacobs TL. Real-time ultrasound-guided percutaneous dilatational tracheostomy: a feasibility study. Crit Care 2011;15(1):R67.

97. Tremblay LN, Scales DC. Ultrasound-guided tracheostomy-not for the many, but perhaps the few or the one. Crit Care 2011;15(2):147.

98. Guinot PG, Zogheib E, Petiot S, Marienne JP, Guerin AM, Monet $\mathrm{P}$, et al. Ultrasound-guided percutaneous tracheostomy in critically ill obese patients. Crit Care 2012;16(2):R40.

99. Tobin AE, Santamaria JD. An intensivist-led tracheostomy review team is associated with shorter decannulation time and length of stay: a prospective cohort study. Crit Care 2008;12(2):R48.

100. Mirski MA, Pandian V, Bhatti N, Haut E, Feller-Kopman D, Morad A, et al. Safety, efficacy, and cost-effectiveness of a multidisciplinary percutaneous tracheostomy program. Crit Care Med 2012; 40(6): 1827-1834.

101. McGrath BA, Bates L, Atkinson D, Moore JA. Multidisciplinary guidelines for the management of tracheostomy and laryngectomy airway emergencies. Anaesthesia 2012;67:1025-1041. 


\section{TRACHEOSTOMY}

\section{Discussion}

Durbin: I would like to make a few comments on the TracMan trial. We've been waiting for that study to be published for at least 2 years. The research group gave us the data in preliminary form and then took so long to write the paper it was frustrating! On the positive side, it was truly amazing that they got so many people to collaborate in the trial. It would have been very difficult doing this trial in the United States. The authors recieved broad-based buy-in and a huge amount of government support. I think their data are really useful. A difference with the United States and British health care systems is that there is little pressure to vacate ICU beds in the United Kingdom. The fact that early tracheostomy didn't alter hospital or ICU stay is not surprising in the United Kingdom system. In the United States, placing a tracheostomy will result in moving a patient to a lower level of care area sooner, out of the ICU, making room for the next patient. I' $m$ happy there was no difference in mortality between early and later tracheostomy. This reassures me that earlier tracheostomy is not seriously harming patients. However, I believe the study did not follow patients long enough to identify late complications. Correct me if I'm wrong.

Napolitano: You are correct. The TracMan trial reported 2-y mortality rates, but no long-term follow-up of complications.

Durbin: So there still may be longterm issues we might want to avoid by waiting to see if a tracheostomy is actually necessary. However, it seems like the majority of patients do well after placement of a temporary tracheostomy.

Napolitano: And there have been no long-term PDT [percutaneous dilata- tional tracheostomy] studies that have shown any harmful effects.

Durbin: But this assertion is based on studies that are quite small. Another area of controversy is who does the tracheostomy? The ENT [otolaryngology] department at University of Virginia rejects PDT as a legitimate procedure. My general surgery colleagues routinely perform PDT in the ICU, but they approach it slightly differently than I do. They begin by making a longitudinal incision and manually or visually identify the cricoid and tracheal rings. I simply use a bronchoscope to direct the percutaneous needle stick and wire placement. Our outcomes are essentially the same; I can't tell any difference in success or problems. I'm very comfortable doing PDTs in obese people, and I think PDTs are safe at least in the short-term. I don't know if it's better for the long-term, as tracheostomy complications in general are higher with obesity. The data are mixed. I have come to believe that even with coagulopathy and platelet issues, there's less bleeding and fewer infections following PDT than open procedures. So I'm in favor of PDTs in almost every circumstance. I'd really like to hear the Hopkins experience when you have all specialties on board.

Berkow: As one of the members of the trach team in my hospital, we've got a really well-oiled machine, and what's nice is that the surgeons who do the trachs are both trauma and otolaryngology surgeons. We've really got a nice agreement on general protocols, and we have a core group of anesthesiologists who do these regularly. It's really made a huge difference; our big problem was the wait time to get to the OR [operating room] for trach. Plus, throughput is a huge issue. I don't know about the rest of you, but every other day, there's an ICU hold or a delay, so getting them out of the ICU earlier in the United
States, I agree, is a big driving factor. So, yes, it works well, but it helps to have a team, and you need a coordinator to line everything up. There are still some patients who don't meet the criteria for PDT for all the reasons mentioned. Those patients still come to the OR, but now it's a much smaller subset of patients.

Napolitano: We do open surgical tracheostomy at the bedside in our surgical ICU all the time. Even if we have to do them open, we don't necessarily go to the OR unless it is a very high-risk patient. It's interesting though, our ENT colleagues always go to the OR. So if the ENT surgeons get a consult for tracheostomy from the medical ICU, they go to the OR. In our surgical ICU, we do open tracheostomy bedside in the ICU all the time; we do them on our ARDS patients and on our ECMO [extracorporeal life support] patients. We have everything that we need at the bedside in the SICU [surgical ICU], including OR light, headlight, bovie electrocautery cart with grounding, and surgical tracheostomy trays.

Berkow: You're lucky. When I was a resident, we did a lot more surgical procedures in the ICU setting: we opened abdomens, we did trachs, and we had some complications as well as space constraints, so it just became policy that you can't do a true surgical procedure in the ICU anymore. That was no longer an option. I'm sure our surgeons would love to do open trachs in our ICU, but, in our institution, we just can't.

Ramachandran: This brought back memories. One of my other experiences in Oxford was with a PDT and an aberrant subclavian artery that was attached to the trachea and went right up into the neck and back into the arm. At tracheal dilation, the artery just avulsed. We had a fiberoptic scope down, and it still didn't prevent the complication and set off 
a study ${ }^{2}$ of vascular anatomy in the neck after that. This technique is really a direct result of those initial adverse events, so I think that using real-time ultrasound for PDTs is a big safety step forward.

Napolitano: I think that's a really important point: you can't predict who will have altered vascular anatomy in the neck and cervical area. So just take a look with real-time ultrasound prior to PDT; everybody has ultrasound in their ICU. It's very easy.

Hess: Representing the RTs [respiratory therapists] who take care of these patients after the procedure, my observation has been that a percutaneous trach leaves a much cleaner stoma than an open trach, which I think contributes to better care after the procedure. When we were first doing these, we were very concerned about the first trach change, where the RTs are very involved. We've actually found that it's easier after a percutaneous trach then an open trach. In fact, we are now doing first trach changes as soon as $5 \mathrm{~d}$ after the procedure, which really facilitates the process of downsizing, using speaking valves, starting nutrition, getting patients decannulated, and so forth.

Napolitano: When you say you do the first trach change, you're changing out the entire tracheostomy tube?

\section{Hess: Correct.}

Napolitano: We don't do that anymore because these tracheostomy tubes can stay in for a very long time. We just change the inner cannula; we don't do any routine tracheostomy tube changes at all except when we're ready to either downsize or go to a fenestrated tracheostomy or if there is a mechanical complication of the tube.

Hess: Yes, that's what I'm talking about. We don't routinely change them at $5 \mathrm{~d}$; I didn't mean to imply that. But if, at $5 \mathrm{~d}$, the patient is off the ventilator and we can use a speaking valve. If we apply a speaking valve and there's not enough room around the trach tube so that the patient can have air movement through the upper airway, then we'll downsize or change to a different style trach. With open trachs, we tend to wait longer, although maybe we don't need to.

Napolitano: I don't think there's any change from our perspective. We would do the first tracheostomy change over a red rubber catheter to make absolutely certain that there's not any movement of the subcutaneous tissue and that we do not create a false tract with the tracheostomy change. The stability of the tracheostomy tract depends on how you do your open trach. Sometimes, when some surgeons do an open trach, they make a huge incision, and there's a lot of tissue distortion. We do a very small $1.5-\mathrm{cm}$ vertical incision, and in the end, you really can't tell the difference between an open trach or a PDT in our unit. Once the trach is in, you can't see the vertical incision.

\section{Hess: So it may relate to technique.}

Napolitano: Yes, I think it's related to technique. Most of us who do open tracheostomies at the ICU bedside have abandoned transverse incisions. We use a vertical incision because you can extend the incision up or down as you need to, depending on where you need to place the tracheostomy tube. That surgical incision ends up being very small. Our RT colleagues help us with the initial tracheostomy operative procedure and help us downsize and do whatever else we need to do. I think there will always be $10-20 \%$ of patients who will need open trachs for some reason or another, related to anatomy, need for systemic anticoagulation, inability to tolerate hypercarbia or hypoxemia, etc.
Durbin: While we discuss tracheostomy, I wanted to mention the other surgical airways that are recommended for airway emergencies. One of the nice things about the PDT is that, even though none of the residents in the anesthesia program really do enough to be competent, they'll all perform tracheal entry a couple times during training. This hands-on exposure makes them more secure and less likely to hesitate in establishing a surgical airway should they be in a cannot intubate-cannot ventilate situation in the future. If they're the most experienced person at the scene, I want them to be able to do whatever's necessary to save a life. If you've helped on a PDT and entered the trachea a few times, you're less afraid of trying a surgical airway to save a life. As a teaching opportunity, I think it's really important for nonsurgical practitioners to have this experience.

Napolitano: I agree totally. I think you can teach anybody to do a PDT with bronchoscopic assistance because you're watching everything that they do; it's just fabulous. I will say I am still a little concerned in an obese person; if you are going to put a trach in percutaneously, be careful about the length. Most of the standard trachs are going to be too short; you really have to pick your trach wisely. We had a patient come from another hospital with a percutaneous trach that was very short, and he was a 450-lb gentleman. You know, we just kept that tracheostomy tube sutured and strapped tight to his neck, and as soon as we could change it out, we did. You have to be mindful of the potential need for longer tracheostomy tubes in obese and tall patients.

Hurford: Lena, what is the role for needle cricothyroidotomy?

Napolitano: In my hands, none.

Hurford: Okay. In anyone's hands? 
Napolitano: I don't think ever. If you're in the ED [emergency department] and you have a trauma patient or any kind of emergent patient who needs an emergency surgical airway, we always make a surgical incision for cricothyroidotomy and place either a size 6 tracheostomy tube or a size 6 ETT [endotracheal tube]. It is too complicated, and it's too difficult to ensure that you're actually in the airway with the needle using the Melker cric kits. We don't use them; we teach our residents to do an open cric. You put your finger in the cric so you know you're in the trachea, and then you place a tracheostomy or ETT.

Ramachandran: We have a difference of opinion because our airway team still does push training for the Melker kit. The NAP4 [Fourth National Audit Project $]^{3}$ in England had some interesting data on narrow-bore versus wide-bore cricothyrotomy kits. The failure rate for narrow-bore kits was quite high; actually, I think only $30 \%$ of them were successful, whereas the wide-bore kits were more likely to be inserted by surgeons and had a much higher success rate of $80-90 \%$.

Berkow: I'd like to point out what's striking in the NAP4 report is that $60 \%$ of all the cricothyrotomies failed, so it was a huge wakeup call about training and knowing how to do it properly. I was going to ask that as well; it's still a matter of debate. In an emergency surgical airway, do you do a PDT or open technique? I know we debate it at our hospital, and there's lots of opinions on both sides.

Napolitano: We do open.

Ramachandran: To add to that, we do have a difficult-airway team in our hospital, similar to what you described. We have an ENT surgeon on it, and the preference of the ENT surgeons on this team is to do a formal tracheostomy at the bedside.
Berkow: Even with our difficultairway team and their experience with so many PDTs, they still advocate an open emergency surgical technique.

Napolitano: I think that will always remain the gold standard. An open cric as an emergency surgical airway.

Collins: To follow up an earlier point, we have the Melker kit in the difficult-airway cart at our institution, although I am surprised in some of my experiences with resident training using simulation cases that some residents do not know that it is available or have no experience with the kit. Having said that, when they work with it on mannequins, they seem more adaptable to its use because they're familiar with the Seldinger technique. On another note, I' $m$ interested in your comments as to why we are so poor in our ability to predict who will be mechanically ventilated for a period of time. If we could predict this better, do you think there would be much less controversy?

Napolitano: I think the TracMan trial $^{1}$ excluded a lot of patients who we all know will require prolonged intubation: the ARDS patients; the COPD patients; the patient who was extubated, failed, and got re-intubated. They excluded all those patients. The TBI [traumatic brain injury] patient, excluded. The problem is in the generic ICU population, which is mostly patients who have pneumonia, aspiration, atelectasis; had a long operation; and things like that. The question in those patients is how we can predict duration of mechanical ventilation. It's really variable because I think now that we do SBTs [spontaneous breathing trials] every day to determine whether we can extubate somebody, we're all surprised when one day somebody fails and the next day they do okay. I don't know how to improve our ability to predict who will require long-term mechanical ventilation. Maybe we should look at their
SBTs every day, and if they fail every day for $4 \mathrm{~d}$, maybe that's a good tool to say they're going to stay intubated for 7 or $14 \mathrm{~d}$. In all of these 3 major studies, the clinicians predicted need for prolonged mechanical ventilation very poorly.

Ramachandran: How about muscle strength? I have a friend who's studying muscle strength in the ICU and the ability to predict who will wean successfully early.

Napolitano: Deconditioned state and poor muscle strength or frailty might be a good surrogate for need for prolonged mechanical ventilation. Would serial vital capacity measurements be predictive? I don't know. Even for weak ICU patients, if their respiratory issues resolve, they may still get extubated and liberated from mechanical ventilation.

Hess: A practical question from the perspective of the RT, something that we run into, and I'm interested to hear your thoughts: how soon can you remove the sutures from the trach after you put it in? What is your practice?

Napolitano: We leave them in about a week. For some of our patients for whom removal of the tube would clearly be problematic, we leave them in longer. At a week, there should be an epithelialized tract, so even if the tube comes out, you should be able to get it back in. I think that before a week there may be a question as to whether you could get it back in without any trouble. Again, I think it falls into whether you are doing $100 \%$ PDTs or you are doing some open tracheostomies. I think it is harder to recannulate early in the open trachs, where you have a surgical incision and the tissues are rearranged a little bit; it's easier to make a false tract. There's 
no science or studies there to tell us, but we keep the tracheostomy sutures in about a week.

\section{REFERENCES}

1. Young D, Harrison DA, Cuthbertson BH, Rowan K, TracMan Collaborators. Effect of early vs late tracheostomy placement on survival in patients receiving mechanical ventilation: the TracMan randomized trial. JAMA 2013;309(20):2121-2129.

2. Shlugman D, Satya-Krishna R, Loh L. Acute fatal haemorrhage during percutaneous dilatational tracheostomy. Br J Anaesth 2003 90(4):517-520.
3. Cook TM, Woodall N, Frerk C, Fourth National Audit Project. Major complications of airway management in the UK: results of the Fourth National Audit Project of the Royal College of Anaesthetists and the Difficult Airway Society. Part 1: anaesthesia. Br J Anaesth 2011;106(5): 617-631. 